\title{
Hand, head, and face: Negative constructions in sign languages
}

\author{
ULRIKE ZESHAN
}

\begin{abstract}
This article presents a typology of negative constructions across a substantial number of sign languages from around the globe. After situating the topic within the wider context of linguistic typology, the main negation strategies found across sign languages are described. Nonmanual negation includes the use of head movements and facial expressions for negation and is of great importance in sign languages as well as particularly interesting from a typological point of view. As far as manual signs are concerned, independent negative particles represent the dominant strategy, but there are also instances of irregular negation in most sign languages. Irregular negatives may take the form of suppletion, cliticisation, affixing, or internal modification of a sign. The results of the study lead to interesting generalisations about similarities and differences between negatives in signed and spoken languages.
\end{abstract}

Keywords: affixation, clause type, cliticisation, iconicity, negation, nonmanual negation, scope, sign language, suppletion, word/sign order

\section{Introduction}

\subsection{Sign languages}

Visual-gestural communication is as old as humanity (Armstrong, Stokoe, \& Wilcox 1995) and appears in many different forms and situations. Limited signed codes may be used by hearing people in situations where speaking is impossible or unpractical, for example by divers when communicating under water. In situations of strong speech taboo, signing may even become a complete alternative mode of communication, as has been demonstrated, for example, by Kendon (1988) for certain Australian Aboriginal communities. However, this article investigates data from sign languages as used in deaf communities 
around the world. These sign languages are natural human languages operating in a visual-gestural modality. Their linguistic signals consist of movements and expressions that are produced with the hands, arms, face, head and torso and are perceived with the eyes. Sign language research since the 1960's has demonstrated that sign languages are full-fledged languages whose linguistic structure, complexity and expressive capacity is in every way analogous to and on a par with spoken languages. This distinguishes the sign languages used in deaf communities from limited signed codes that are used by hearing people in certain restricted situations only, as well as from co-speech gestures used by hearing people. Wherever deaf people come together to form communities, sign languages develop naturally and then constitute the primary means of communication for the deaf community using the sign language. This again distinguishes the sign languages used in deaf communities from secondary sign languages used as alternative modes of communication in hearing societies. For the purpose of this article, only primary sign languages used in deaf communities are considered.

The sign languages used in deaf communities are usually minority languages that co-exist with the spoken majority language or languages. Although they are thus in a situation of constant language contact, sign languages are in no way derived from surrounding spoken languages and do not represent spoken languages "on the hands". Rather, every sign language has its own unique structure at every level of linguistic organisation which can be and often is radically different from the co-existing spoken language or languages. Deaf communities in turn are increasingly being recognised as linguistic and cultural minorities that use sign languages as their legitimate primary means of communication.

\subsection{Methodology and data}

This paper reports on some results from the first-ever large typological study across sign languages around the world. Data from 38 sign languages ${ }^{1}$ have been compiled and analysed for this project, and they reveal striking patterns of both similarities and differences across sign languages. Most of the data presented in this paper have been specifically generated for the typological project and have been previously unpublished. Many co-researchers around the world have contributed valuable data from their respective sign languages (see Acknowledgements), and without their help this study would not have been possible. Throughout this article, unless another source is cited, the data, observations and examples are based on the responses by co-researchers to a

1. This represents a substantial portion of the world's known sign languages. The Ethnologue (Grimes 1996) lists 103 sign languages, several of which are extinct. 
Table 1. Sign languages represented in the typological project

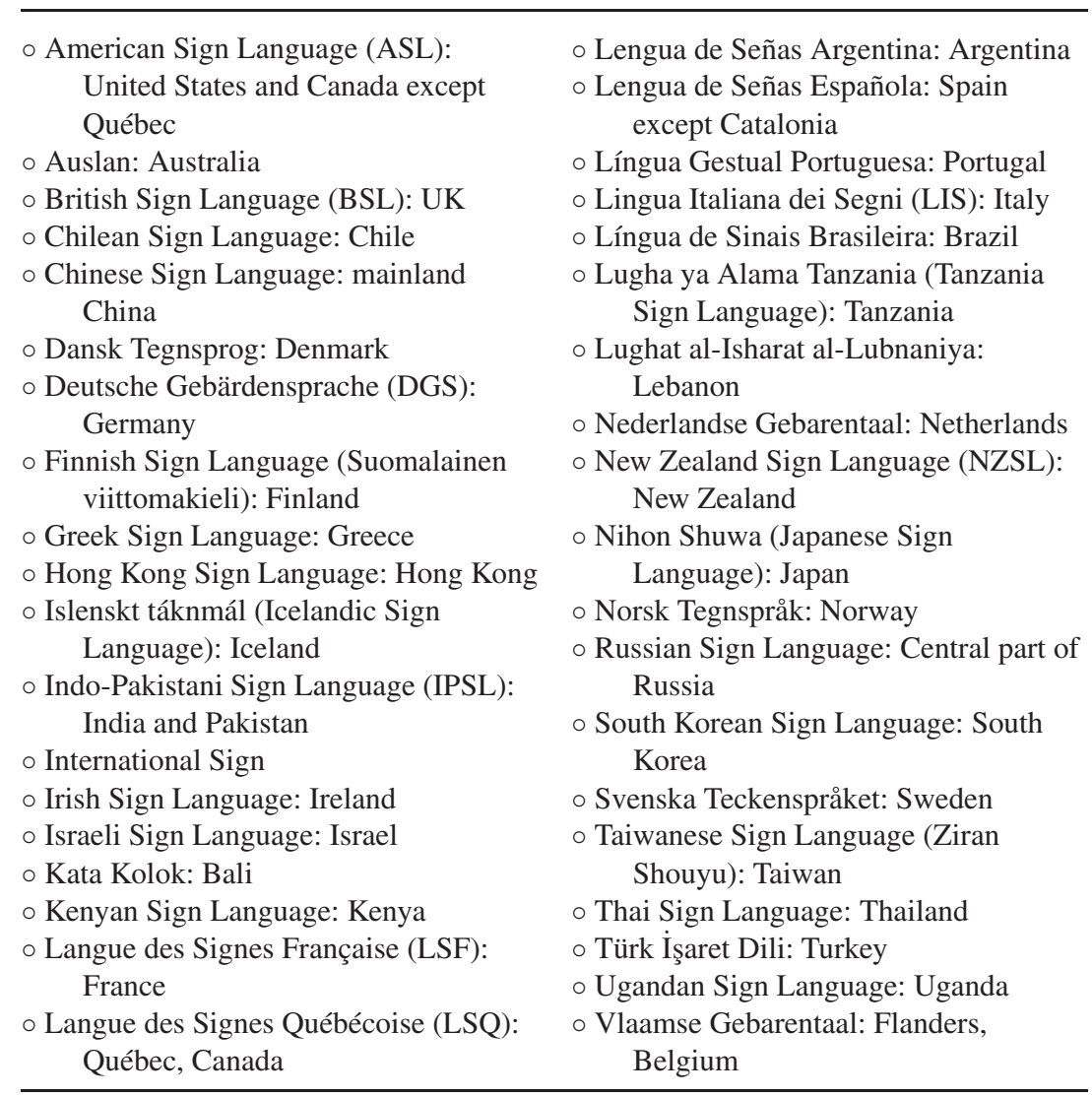

detailed questionnaire about negatives and interrogatives, which often included visual data in the form of pictures or video.

Table 1 lists the sign languages represented in the typological project, together with the region where they are used. A more extensive table detailing the data used for the study can be found in Zeshan (2004), which also includes details about the methodology of data collection and associated problematic issues. The present article also includes data from four additional sign languages. In Turkey and in Lebanon, I have carried out fieldwork myself, and information from China and from Bali has become available for the project in the meantime.

The geographical distribution of the sign languages represented in the typological survey is as follows: 


$\begin{array}{ll}\text { North America: } & 2 \\ \text { South America: } & 3 \\ \text { Europe: } & 16 \\ \text { Africa: } & 3 \\ \text { Asia: } & 11 \\ \text { Australasia: } & 2\end{array}$

International Sign is not included in this list because it is a pidgin that has developed and functions as a contact language during international conferences between users of mutually unintelligible sign languages (cf. Webb \& Supalla 1994). It therefore has no obvious geographical location, although it may be noted that it mainly draws on European and North American sign languages.

The uneven distribution over geographical regions is noticeable and warrants a few words of explanation. First of all, some regions have fewer sign languages than others. For example, North America represents a large geographical area with few sign languages. American Sign Language is used all over the United States and in the English-speaking parts of Canada, while Langue des Signes Québécoise is used in the French-speaking part of Canada. For other regions, we can assume that substantially more sign languages exist but have not been documented or even identified yet. This is true of Africa in particular, and also, to a lesser extent, of Asia, although there are already a number of Asian sign languages in the survey. Finally, the large number of European sign languages is due to the fact that there is much linguistic variety as well as sufficient research resources to rely on. Although for most European sign languages published sources are insufficient for our purposes or simply not available yet, it has at least been possible to rely on a number of co-researchers working in European countries. By contrast, in many countries in Africa, Asia and South America there is currently no or very little sign language research.

As may be inferred from the uneven geographical distribution of the sign languages, no sampling has been done to try to ensure equal representation of sign languages from different regions and language families. This approach, which would be unusual and indeed unacceptable for a typological survey on spoken languages, is necessary given the current state of research in sign language linguistics. First of all, membership in a language family of whatever kind is simply not known for many sign languages. Moreover, the notion of "language family" itself is not at all clear in relation to sign languages and may turn out to be rather different from the language family models that exist for spoken languages (cf. the introduction in Zeshan, forthcoming). These two factors make sampling by language family impossible at present. Another reason for the absence of sampling is the fact that data from a variety of sign languages are so scarce and hard to come by anyway. It has been an important part of the typological project to actually generate the language data that had 
been unavailable before. Since the material that has become available for the survey still covers relatively few sign languages and there is no way of knowing beforehand what might be the typological relevance of a particular sign language, any and all available data have been incorporated into the study.

This approach also entails that the results presented here give evidence of the possible range of forms and patterns across sign languages rather than being statistically valid generalisations. Much of the sign language literature to date conveys the impression that sign languages are very similar to each other in structure. This is not true for all domains of grammar, and certainly not for either interrogatives or negatives. Finding out exactly where sign languages are similar to each other, where they differ, and why this should be so, is itself part of building up a theory of variation and thus one of the aims of sign language typology. In a first typological survey, the aim can only be to demonstrate the kinds of differences and similarities that we find across sign languages around the world. On the other hand, it makes little sense to state generalisations in terms of percentages, so as to say that, for example, $80 \%$ of sign languages have negative derivation and $20 \%$ lack this process. Since numerical values may give a distorted picture due to the uneven distribution of sign languages, the discussion in the following sections does not rely on percentages. Although I will draw generalisations from the data, these will not be phrased in terms of percentages and only occasionally in terms of absolute numbers. What we can demonstrate is the range of structures to be found across sign languages, as well as tendencies that emerge either from all sign languages in the survey or from sign languages in a particular region.

\subsection{Negation in signed and spoken languages}

Negation is a wide field of study (cf. Horn 1989, Croft 1991, Dobrin, Nichols, \& Rodriguez 1991) that includes many sub-parameters because there are so many places in a sentence that can be negated independently of each other. We thus find, among others, clause negators ('not'), negative pronouns ('nobody'), negative responses ('no'), negative adverbs ('never'), and negative coordination ('neither ... nor'). Since it would be beyond the scope of this article to cover all possible manifestations of negation in sign languages, I will limit myself to a few sub-parameters that are either central to any study of negation or particularly interesting from a typological point of view.

The problem of accurately delimitating the domain of negation and, in particular, of distinguishing between grammatically negative and semantically negative contexts is similar for both signed and spoken languages. As is the case with many linguistic categories, the borderlines may sometimes become blurred and it may be difficult to neatly categorise a particular item one way or the other. For the purpose of this article, semantically negative items such as 
'refuse', 'wrong', 'deny', 'doubt', etc. are not included in the analysis. That is, unless explicitly stated otherwise, this article deals with instances of grammatical negation and its realisation in sign languages.

The parameters covered in the typological project are listed in Table 2. Some of these would be included in any study of negation, while others are particular to sign language research. The latter especially applies to nonmanual negation, negative marking that is conveyed by head movements and facial expressions in sign languages. This mechanism has few parallels in spoken languages, except in cases where negation would be conveyed by a particular intonational pattern, since nonmanual signals in sign languages are equivalent to intonation patterns in spoken languages (cf. Sandler 1999). In sign languages, nonmanual negation is one of the most important parameters to look at, so this aspect of negation will be covered in detail in Section 2. I will discuss the form of nonmanual negative marking, its status and scope, and its relationship with manual marking of negation by negative signs.

Clause negators in sign languages include all manual signs that negate a whole clause rather than a particular constituent only. The project has covered both basic clause negators, which convey negative polarity only and have no other meaning components, and special clause negators with additional functions such as emphatic negators, negative existentials, negative modals, negative imperatives, and so on. Manual clause negators are discussed in detail in Section 3. Some negative constructions, such as negative raising, or negation and completion, have been investigated separately in the project, but are not included in this article as a separate section.

In addition to sentence-level negation, constituent negation has also been investigated, though the data are more sketchy and less reliable for some subparameters in this domain. Possible manual and nonmanual mechanisms for constituent negation have been considered, but the results are not substantial enough to be included here. On the other hand, irregular negatives in the form of negative derivation and negative suppletion are extremely interesting and will be covered in detail in Section 4. Sign languages also use a variety of signs that would seem to be negative quantifiers, adverbs, and pronouns, but their grammatical status is often unclear at this point, so that a detailed discussion has to be deferred until more information becomes available. Finally, the relationship between signs and gestures as well as facial expressions and nonmanual marking is of great interest to sign language research. Results from this domain are mentioned throughout the article rather than in a separate section.

Negation has been studied quite extensively from a typological point of view, based on larger or smaller samples of languages. The literature includes studies of negation in individual regions or language families (Zanuttini 1997 for Romance languages, Hovdhaugen \& Mosel 1999 for Oceanic languages, Bernini \& Ramat 1992 for European languages), case studies of languages from differ- 
Table 2. Parameters of investigation for negatives

\begin{tabular}{|c|c|c|}
\hline $\begin{array}{l}\text { NONMANUAL } \\
\text { NEGATION }\end{array}$ & $\begin{array}{l}\text { marking } \\
\text { status } \\
\text { scope } \\
\text { combination with manual negation } \\
\text { frequency of manual and nonmanual n } \\
\text { use as negative response }\end{array}$ & egation \\
\hline CLAUSE NEGATORS & $\begin{array}{l}\text { position } \\
\text { paradigm }\end{array}$ & $\begin{array}{l}\text { basic clause negators } \\
\text { other negators } \\
\text { basic clause negators } \\
\text { other negators }\end{array}$ \\
\hline $\begin{array}{l}\text { SPECIAL NEGATIVE } \\
\text { CONSTRUCTIONS }\end{array}$ & $\begin{array}{l}\text { negative transport/raising } \\
\text { negative and other categories } \\
\text { negative and existential } \\
\text { negative and completive } \\
\text { negative marking in non-negative cont }\end{array}$ & exts \\
\hline $\begin{array}{l}\text { CONSTITUENT } \\
\text { NEGATION }\end{array}$ & $\begin{array}{l}\text { mechanisms } \\
\text { irregular negatives } \\
\text { negative quantifiers/adverbs/pronouns }\end{array}$ & $\begin{array}{l}\text { negative particle } \\
\text { nonmanual negation } \\
\text { intonation/stress } \\
\text { other } \\
\text { negative derivation } \\
\text { negative suppletion } \\
\text { inherently negative items } \\
\text { syntax }\end{array}$ \\
\hline $\begin{array}{l}\text { GESTURAL } \\
\text { SUBSTRATE }\end{array}$ & \multicolumn{2}{|c|}{$\begin{array}{l}\text { nonmanual marking and facial expressions } \\
\text { signs and gestures }\end{array}$} \\
\hline
\end{tabular}

ent language families (Kahrel \& van den Berg 1994), and general typological surveys (Dahl 1979, Payne 1985, Dryer 1988). However, no previous publications include any data from sign languages. Although it is increasingly being recognised that sign language research has much to offer for linguistic typology (cf. Dotter 2001), sign languages are still largely absent from typological studies, in particular in the context where they should most obviously be included, that is, large-scale typological surveys covering substantial samples of the world's languages.

This situation has several reasons that cannot be addressed in detail here. One of the main problems seems to be the general unavailability of sign language data in a form that can be used by language typologists. Even for the sign languages that can be considered relatively well-studied, such as American Sign Language and British Sign Language, no reference grammars are 
available. For most sign languages in Asia, Africa, and South America, regions that include some of the largest deaf communities in the world, basic linguistic information is only just becoming available. Accordingly, a large-scale typological study across sign languages would not have been possible as recently as five years ago. As more and more information about sign languages becomes available, it is important to make the results of this kind of research accessible to linguistics in general and linguistic typology in particular. Over its short 40-year history, sign language research has developed a substantial terminology of its own, as well as its own conventions of data representation. Problems with the representation of visual, three-dimensional language data also present a major obstacle to the accessibility of sign language research results for nonspecialists.

This first case study in sign language typology is intended as a step towards bridging the current information gap between sign language research and linguistic typology. Sign language typology uses methodologies that have arisen out of research in linguistic typology and applies these to data drawn from sign language research. Conversely, sign language data, examined from a typological point of view, feed back into our view of human language in general and linguistic typology in particular. Therefore, the aims of sign language typology are two-fold: to describe crosslinguistic variation across sign languages from a typological point of view, and to compare the results of this research with what we know about the typology of spoken languages. ${ }^{2}$ This adds an exciting new perspective to the study of human language by considering the effect of language modality on language structure.

The topic of modality differences between signed and spoken language is not new, at least not among sign language researchers. It has been discussed in the sign language literature since the 1970's (e.g., Stokoe 1978, Mandel 1977, Bellugi \& Fischer 1972, DeMatteo 1977). These and subsequent publications have repeatedly brought up several subject domains that seem to be of particular relevance: simultaneity versus sequentiality (Dotter \& Holzinger 1995), iconicity versus arbitrariness (Armstrong 1983, Karlsson 1984), the role of space in sign language grammar (Emmorey \& Reilly 1995), and, most recently, the role of gesture (Armstrong, Stokoe, \& Wilcox 1995). What has been missing in all this literature to date is a strong empirical basis for the sign language side of the comparison that would include data from many different sign languages across geographical and genetic boundaries. While few linguists nowadays would dare make any claim about spoken language in general based on English and a couple of other European languages, it was not uncommon in

2. I have explained the aims and methodologies of sign language typology in more detail in Zeshan (2004). 
the past to talk about "sign language" in general on the basis of just a few, almost invariably European and North American, sign languages. Due to the lack of sign language data from most parts of the world, this situation was perhaps inevitable, but is becoming increasingly untenable as more information from genetically and geographically unrelated sign languages becomes available. The study on interrogatives and negatives is intended as a step towards building up this strong empirical basis.

The information in the following sections is presented so as to be accessible to the non-specialist in sign language research and has been cast in a typological framework. All technical terms from sign language linguistics are explained in the text. Notation and transcription conventions are listed in the appendix at the end of the article. Figures depicting signs from various sign languages have been added to illustrate the main points. In discussing the significance of the sign language data, I draw upon the existing literature about the typology of negation across spoken languages.

\section{Nonmanual negation}

The term NONMANUAL NEGATION includes negative marking involving any part of the body other than the hands. Head movements and facial expressions commonly occur with negation in sign languages. Nonmanual features in sign languages are suprasegmental, that is, they spread over a smaller or larger string of manual signs in a clause, just as intonation in spoken languages is superimposed on spoken words. Nonmanual marking in sign languages and intonation in spoken languages are also similar in the range of functions they perform. For example, particular facial expressions and head/body postures are used to signal polar questions in sign languages in the same way that a particular intonation contour, mostly rising intonation, marks polar questions in many spoken languages. Both nonmanual marking and intonation can serve as the only marker of a grammatical function. In sign languages, nonmanual marking is paramount in the identification of clause types, such as conditional, interrogative, subordinate, and, last but not least, negative clauses. A particular nonmanual configuration used for a particular grammatical function is called a NONMANUAL MARKER.

Since nonmanual markers are superimposed on manual signs in a clause, they can have variable "scope". In sign language linguistics, the SCOPE of a nonmanual marker is defined as all the manual signs that the nonmanual marker co-occurs with. The minimum scope of a nonmanual marker is a single sign, the maximum scope is the whole clause. If a headshake is used in a sign language to signal negation, all manual signs that are co-temporaneous with the headshake are said to fall under the scope of this nonmanual negation. Note that this definition of scope as a technical term in sign language research is 
not necessarily the same as other definitions of the same term used in spoken language linguistics. The scope of nonmanual negative marking, along with its grammatical status, is an important parameter for comparing negation across sign languages.

With respect to nonmanual negation in sign languages, it is to be noted that the analogy between nonmanual marking and intonation becomes problematic from a functional point of view. While nonmanual negative marking is extremely common in sign languages, indeed universal across the languages in our sample, the corresponding phenomenon in spoken languages, marking of negation by intonation, is extremely rare. Moreover, nonmanual negation can be and frequently is the only marker of negation in many, though not all, sign languages. A corresponding situation where negation would be marked by a particular intonation contour only has, to the best of my knowledge, never been reported for any spoken language, and none of the available typological surveys mentions intonation as a separate strategy to express negation.

It seems, therefore, that nonmanual negation is a domain where sign languages differ considerably and systematically from spoken languages. Thus, it is also a domain that should be particularly interesting from a typological point of view. In sign language research, nonmanual aspects have been recognised as a particularly important characteristic of sign languages at an early stage and have subsequently attracted much attention in the literature (e.g., Baker \& Padden 1978 for American Sign Language, Coerts 1992 for Sign Language of the Netherlands, Engberg-Pedersen 1990 for Danish Sign Language, Pizzuto, Giuranna, \& Gambini 1990 for Italian Sign Language, Zeshan 2000a for IndoPakistani Sign Language). At the same time, nonmanual negation is one of the domains where the typological survey across sign languages has revealed the most striking results in terms both of similarities and of differences. The following sections describe the form, the grammatical status, and the scope of nonmanual negative marking, as well as the combination of manual and nonmanual negation.

\subsection{Form of nonmanual negation}

Two kinds of nonmanual signals are associated with negation in sign languages: facial expressions and head movements. In many cases, the form of these signals tends to be very similar across sign languages, whereas the status and scope of nonmanual negative marking can differ quite radically. I will first give a survey of the forms we find across the sign languages in our data and then proceed to describe crosslinguistic differences in the grammatical patterns associated with the various negative markers.

As far as head movements are concerned, we find three different types. A repeated side-to-side movement of the head is the most common negative marker 
across sign languages. In fact, it is found in all sign languages in our data. Even sign languages that use other head movements also have a side-to-side headshake in addition to the other possibilities. Since headshake negation consists of a repeated movement, it can easily have scope over more than one sign. Among the three possible head movements, the negative headshake is therefore the most interesting nonmanual marker as far as its combination with manual signs is concerned (see Section 2.4).

A head movement that is similar to the negative headshake is a single sideward head turn. In this case, the head is turned to one side and remains in this position. Its relation to the side-to-side headshake is not entirely clear, but it seems that it can often be interpreted as a reduced form of the side-to-side headshake (see discussion in Section 2.2). The negative head turn is used in Irish Sign Language, Greek Sign Language, Langue des Signes Québécoise (Canada), British Sign Language, Chinese Sign Language, Vlaamse Gebarentaal (Belgium), and Russian Sign Language, but it is possible that it may be used in other sign languages as well where it has not been reported or has been subsumed under the negative headshake.

The third type of negative head movement is quite different from the other two and involves a backward tilt of the head (see Figure 1). This form is clearly an areal feature and is found in sign languages around the Eastern Mediterranean. It thus occurs in Greek Sign Language, Türk İşaret Dili (Turkey), and Lughat al-Isharat al-Lubnaniya (Lebanon). It is certainly no coincidence that the same head movement is also used as a negative gesture by hearing people in the same region. In both cases, the backward head movement is regularly accompanied by raised eyebrows. However, there is no complete geographical overlap between the head gesture and the nonmanual marker. The negative head tilt is used among hearing people in parts of Italy (Morris 1979) and in Israel, but it is not found in Lingua Italiana dei Segni nor in Israeli Sign Language. Moreover, the head gesture when used by hearing people in the region is often accompanied be a dental click sound. This click sound has not been reported for any of the sign languages and is probably not a feature of the nonmanual negative marker. There are thus subtle differences in both form and distribution of the head movement between the gesture used by hearing people and the nonmanual marker used by signers in the same region.

Although there is very little systematic research on this topic, it does seem that in general, head movements as well as facial expressions used in negatives in sign languages tend to be very similar or identical IN FORM to nonmanual expressions of negation used by the surrounding hearing communities in the same region. This in itself is not surprising, given that sign languages develop in constant contact with the majority hearing communities. However, it also seems clear that nonmanual expressions for negation in sign languages and in hearing communities are not always identical IN USE. That 


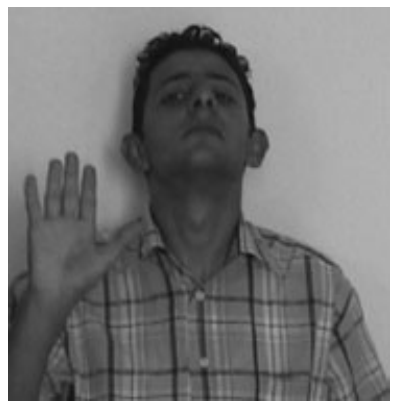

Figure 1. Backward head tilt in Türk Işaret Dili (Turkey)

is, nonmanual markers in sign languages are often used in a much more systematic way, and there are many genuinely grammatical constraints governing the use of individual nonmanual markers, in particular in the domain of head movements. Therefore, in many instances we may think of nonmanual markers as sophisticated grammaticalised extensions of the conventional nonmanual expressions used in co-existing hearing communities. On the other hand, sign languages also make use of communicative gestures, both manual and nonmanual, and their use may be identical to the way these are used in coexisting hearing communities. Since, unlike in spoken languages, both signs and gestures share the same modality, it is notoriously difficult to distinguish between the two. In the remainder of Section 2, we will see examples of the differences in the status of various nonmanual expressions across sign languages.

In addition to head movements, there are a large number of facial expressions that regularly occur in negative clauses. However, their status as grammatical markers is often questionable (see Section 2.2). Accordingly, they tend to be less obligatory and more variable than head movements. Since there are so many unresolved questions with respect to these facial expressions even in sign languages that are comparatively well-documented, the discussion in the following sections will mainly concentrate on head movements. There are, however, a few interesting issues in some sign languages with regard to the co-occurrence of and interaction between head movements, facial expressions, and manual signs that will be discussed in more detail in Sections 2.3 and 2.4.

To give a brief overview of the kinds of facial expressions that can accompany negative clauses, the following facial features, in varying combinations, regularly occur in negative clauses across many sign languages in our data:

- eyebrows lowered and/or drawn together/frowning;

- eyes narrowed and/or squinted; 


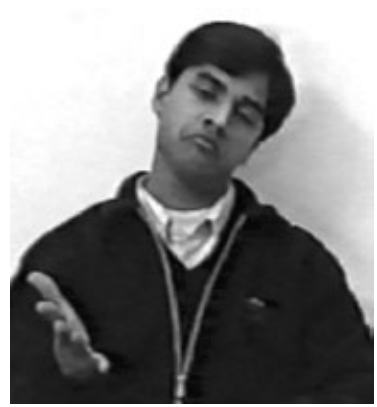

(a) Corners of the mouth down

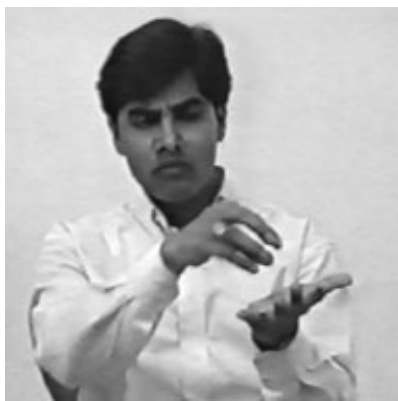

(b) Lowered brows/nose wrinkling

Figure 2. Negative facial expressions in Indo-Pakistani Sign Language

- lips spread or pursed or corners of the mouth pulled down;

- nose wrinkling.

Two examples of different combinations of facial features are represented in Figure 2, from Indo-Pakistani Sign Language (see also example sentences in Section 2.3). Some other facial expressions are more restricted to individual sign languages or even to particular negative signs in a language. The following markers thus seem to be comparatively rare across sign languages:

- In Thai Sign Language, puffed cheeks regularly occur with two negative existentials (NOTHING). Türk İşaret Dili (Turkey) has a construction with puffed cheeks co-occurring with a predicate rather than with a negator.

- A mouth gesture with an air puff is used with the sign ENDNU-IKKE ('not yet') in Dansk Tegnsprog (Denmark), where the air puff can occur by itself as a substitute for the manual sign. A "whistling" mouth gesture also appears with the negator ZERO in Israeli Sign Language when it is used as a negative completive.

- Tongue protruding is used in New Zealand Sign Language as an intensifier with the negator NOTHING, and also occurs with the signs NOT-ME and NOTHING-ME, which are expressions of denial and disavowal. Vlaamse Gebarentaal (Flanders, Belgium) uses this facial expression with signs for 'nothing'.

- Taiwanese Sign Language has several negatives with unusual facial expressions including NOT-YET and NOT-HAVE accompanied by tongue wiggling (-tw), and NOT accompanied by a mouth pattern with a repeated bilabial stop ( $(-\mathrm{bb})$. Both of these facial expressions can also be used by themselves as a nonmanual equivalent of the corresponding signs, although a combination with a manual sign, and also with headshake negation, as shown in the responses in (1) and (2), may be more frequent. Positive re- 
sponses also have nonmanual counterparts (teeth together, -tt, with FINISH, and a round mouth shape, - oo, with HAVE).

$$
\begin{aligned}
& \text { Taiwanese Sign Language } \\
& \overline{\text { YOU GO }}^{\text {brow raise }} \\
& \text { 'Are you going?' } \\
& \text { Taiwanese Sign Language }
\end{aligned}
$$

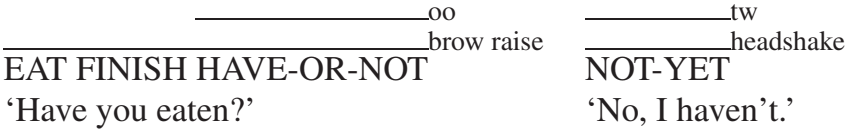

\subsection{Grammatical status of nonmanual markers}

It has long been recognised in sign language research that nonmanual features signaling clause types such as interrogatives, negatives, and conditionals are much more than expressions of emotion and affect (cf. Liddell 1980 and Bellugi \& Klima 1990 about "affective facial expressions" and "linguistic facial expressions"). They are an integral and very important part of the grammar of all sign languages investigated so far. However, the details of this standpoint are less obvious, and it is often difficult to decide whether a particular component of a nonmanual signal has a syntactic, a pragmatic, or an affective function. It may also be hard to tell whether two nonmanual features are variants or separate markers with distinct functions. The task is made more complicated by the fact that nonmanual signals typically consist of more than one sub-feature, not all of which are necessarily obligatory. As far as nonmanual negation is concerned, the co-occurrence of both head movements and facial expressions is typical across sign languages. However, it is widely reported that the two types of signals do not have the same status. This section discusses arguments and issues related to the grammatical status of nonmanual markers, including their use as obligatory or optional markers and particular restrictions or grammatical rules applying to their use in negative clauses.

For many sign languages for which there is information about this in the data, the grammatical status of facial expressions that can accompany negation is reported to be uncertain. Several factors do seem to indicate that facial expressions are often not part of the grammar of sign languages in a strict sense. Arguments come from their optionality in clauses, the absence of clear-cut rules for their use in clauses, and their use in conjunction with individual signs.

First of all, facial expressions at the clause level are considerably less obligatory than negative head movements. While headshake negation and other head

3. Transcription conventions used to represent signed utterances are summarised in the appendix at the end of the article. 
movements are rarely entirely obligatory, they do tend to occur with great regularity in negative clauses in the large majority of sign languages. Facial expressions, on the other hand, are much less stable both in terms of form and in terms of obligatoriness. Moreover, it is often reported that facial expressions alone cannot signal negation in the absence of other forms of manual or nonmanual negation, while negative head movements often do function as the only negator in a clause. The "strength" of nonmanual marking through facial expressions is widely reported to vary greatly and involve a large number of possible facial features in various combinations, which could be likened to the variability of the "tone of voice" in spoken language. More importantly, it is usually not possible to formulate clear-cut rules as to when a nonmanual facial expression has to be used and when it cannot be used. This is in marked contrast with the many rules that govern the use or absence of negative head movements across sign languages. A rare counterexample comes for Svenska Teckenspråket (Sweden), where a particular negative facial expression is used for contrastive negation as a rejection of what has been asserted or implied before (Bergman 1995: 96). The negative facial expression thus typically occurs in dialogues, but is not used in a negative polar question or as a response to such as question, since a polar question does not assert anything that could be contradicted (examples $3 \mathrm{a}$ and $3 \mathrm{~b}$ ). However, facial negation still cannot function as the sole negator in a clause and would be interpreted as an affective facial expression without an accompanying headshake.

Svenska Teckenspråket (Sweden)
a.
INDEX-fl NOT MEMBER
headshake, face-neg
'He is not a member.' (Bergman 1995: 96)
b.

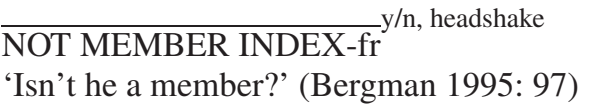

Another unusual instance is the "puffed cheeks" facial expression in Türk Işsaret Dili (Turkey) mentioned in the previous section. This facial expression can act as the sole negator in a clause, without any accompanying negative head movement or manual negative, and is the only such instance in the data. However, the construction is itself rather marginal in the language (see Zeshan 2003). In the large majority of sign languages, it thus does seem that negative facial expressions at the clause level are not part of the grammatical structure of the language.

One environment where negative facial expressions of various kinds do occur with great regularity is in combination with individual signs, that is, at the lexical level. A number of examples have been given in the previous section 
from a variety of sign languages. In these instances, the negative nonmanuals do seem to be largely obligatory. For example, the air puff is said to be obligatory together with the sign ENDNU-IKKE 'not yet' in Dansk Tegnsprog (Denmark). The protruding tongue with NOTHING in New Zealand Sign Language particularly occurs in specifiable environments in one-word utterances and at the end of a clause (McKee 2002). However, these facial features are essentially word-based and do not function as independent clause negators in the way that negative head movements do. Although the Taiwanese Sign Language expressions - bb and - tw can appear by themselves as negative responses in place of the corresponding manual signs, this is a very limited environment. It does not imply that $-\mathrm{bb}$ and - tw can co-occur with and negate any signs as regular nonmanual clause negators. Rather, facial expressions associated with negative signs can be treated like other nonmanual features that are integral parts of individual signs, for example, puffed cheeks with a sign for 'fat', or upward eye gaze with a sign for 'God'.

As may be inferred from previous remarks, negative head movements do generally have a definite grammatical status in sign languages around the world. Of the three head movements described in Section 2.1, the single sideward head turn is the most problematic to assess and also the least documented negative nonmanual. However, similarities in its behaviour across different sign languages suggest that it is best considered a reduced form of the side-toside headshake. For Greek Sign Language, Antzakas (2002) notes that both a side-to-side headshake and a backward head tilt are sufficient by themselves to negate a clause in the absence of any manual clause negator, as in (4). However, a sideward head turn cannot usually negate a clause by itself. Moreover, the head turn cannot occur by itself at the end of a clause, whereas the other two head movements can be placed after the last manual sign to negate the clause (example 5). Neither (4) nor (5) would be possible with a negative head turn instead of the other two markers, and this is strong evidence for the "weak" nature of the negative head turn.

Greek Sign Language

KNOW FACE INDEX3 / WHERE REMEMBER headshake

'I know his face, but I don't remember where from.' (Antzakas 2002)

Greek Sign Language

INDEX1 AGAIN HELP INDEX3 headshake/head back

'There is no way for me to help him again.' (Antzakas 2002)

In addition, some predicates in Greek Sign Language (and other sign languages) with a "psychologically negative" meaning can combine with negative head movements without necessarily resulting in a negative clause, and in 
this context the negative head turn again stands out as different. In (6a), the combination of AVOID with a headshake or backward head tilt results in an ambiguous sentence which can have either a positive or a negative reading. By contrast, a head turn will result in a positive reading only in (6b). This is naturally explained by assuming that the head turn, as a weaker form of negation, does not carry enough negative force to affect the polarity of the clause. The head turn then only signals dislike or avoidance, but not negative polarity.

$$
\text { Greek Sign Language }
$$

a.

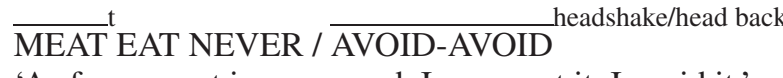

'As far as meat is concerned, I never eat it, I avoid it.'

'As far as meat is concerned, I never eat it, (but) I do not avoid it.' (Antzakas 2002)
b. $\overline{\text { MEAT }}^{\mathrm{t}}$ EAT NEVER / head turn
'As far as meat is concerned, I never eat it, I avoid it.' (Antzakas 2002)

In British Sign Language, the negative head turn is a part of specific negation signs rather than a way of negating a whole clause, which is done by way of the side-to-side headshake (Sutton-Spence \& Woll 1999: 73-74). In Langue des Signes Québécoise (Canada), the head turn occurs on signs that incorporate negation by participating in a negative derivational process (Berthiaume \& Rinfret 2000). In all these cases, the negative head turn is dependent on a manual negative sign that it co-occurs with because it is too weak to function as a negator on its own.

As far as the negative side-to-side headshake and the backward head tilt are concerned, there is no doubt that these are an integral part of the grammar in the sign languages where they occur. Evidence for the status of these head movements chiefly comes from the large number of specific grammatical rules that govern their behaviour in different sign languages. Rules pertaining to the scope of negative head movements are discussed in detail in Section 2.3, while Section 2.4 deals with rules governing the combination of manual and nonmanual negation. This section is concerned with general characteristics of the status of negative head movements and their comparison across sign languages.

One of the most striking results of studying nonmanual marking crosslinguistically is that one and the same nonmanual marker can have the same form, but a very different status in different sign languages. This is especially true of headshake negation. As mentioned before, all sign languages in our data have headshake negation. However, its grammatical status varies considerably from language to language. As shown in example (7), a headshake by itself is not 
sufficient to negate a clause in Nihon Shuwa (Japan). A manual clause negator must be present and is most often accompanied by headshake negation, although manual-only negation is also possible.

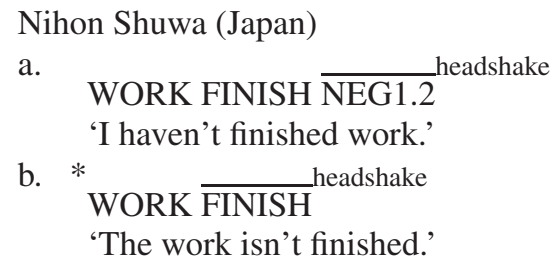

A similar situation seems to hold for Kata Kolok (Bali), where headshakeonly negation does not seem to occur (Gede Marsaja, pers. comm.). However, the two languages are exceptional in this regard. For the majority of sign languages in the corpus (26 out of 38), headshake-only negation has been confirmed to be possible, with the other sign languages currently lacking information on this point. The frequency of headshake-only negation is again quite variable. At the far end of the scale, several sign languages use headshake negation as the most frequent and/or most basic clause negation strategy. This is reported for several Scandinavian sign languages (Norway, Sweden, Finland, and maybe Denmark). In Svenska Teckenspråket (Sweden), headshake-only negation is used in minimal sentences such as weather sentences (Bergman 1995). With few exceptions, the headshake occurs in all negated sentences either with or without a manual negative. In Finnish Sign Language, it is even unclear whether there is a basic manual clause negator at all or whether the headshake is the only basic clause negator available in the language (see Section 3.1 about basic clause negators). In other cases, such as Lengua de Señas Española (Spain), headshake-only negation is possible, but relatively uncommon. Maximally flexible systems such as Indo-Pakistani Sign Language allow all possibilities: manual-only, nonmanual-only, and a combination of both. A combination of manual and nonmanual negation is probably the most common strategy crosslinguistically, followed by headshake-only negation. Manual-only negation occurs more rarely and is uncommon or impossible in several sign languages.

In some cases, the rules for the use of headshake negation go beyond the question of frequency, but involve more subtle grammatical distinctions at the clause level. Hong Kong Sign Language has a particularly interesting pattern with respect to headshake negation. A headshake can negate a clause by itself, but only in the case of an event predicate (example 8). With adjectival or stative predicates, headshake-only negation is not possible and a manual clause negator must be present (example 9). 
a.

HOUSE $\overline{\text { NOT }}{ }^{\text {fadshake }}$ face
'The house isn't far.' (see Figure 5,

b. * * HOUSE $\overline{\text { FAR }}$ headshake

'The house isn't far.'

For the geographically more restricted backward head tilt, we also find clear grammatical rules. In Greek Sign Language and Türk İşaret Dili (Turkey), this head movement preferably combines with particular negator signs (Section 2.4), and its scope is mostly limited to a single sign, with a few interesting exceptional patterns (Section 2.3). For Lughat al-Isharat al-Lubnaniya (Lebanon), the occurrence of the backward head tilt for negation has been established, but details of its use have not been investigated. All sign languages where the backward head tilt occurs also use a negative headshake in addition.

In a number of sign languages in the corpus, there is one possible exception to the status of headshake negation as a grammatical device. This concerns the use of headshakes in grammatically non-negative contexts. That is, a headshake may occur in a sentence that has no negative meaning and where its form, function and distribution are of a different nature. In several sign languages, a particular type of headshake can convey an adverbial meaning similar to English unfortunately (examples 10 and 11). In this case, the headshake is articulated much more slowly and extends over the whole sentence, sometimes beginning before the first manual sign. Headshakes in grammatically positive, but psychologically negative contexts have been reported for New Zealand Sign Language, Indo-Pakistani Sign Language (Zeshan 2000b), Nihon Shuwa (Japan), Thai Sign Language, and British Sign Language (Sutton-Spence \& Woll 1999: 94). On the other hand, a slow headshake can also indicate a strong positive feeling or an extreme degree (example 12). This seems to be less common, but is used at least in New Zealand Sign Language and Irish Sign Language.

Indo-Pakistani Sign Language

INDEX1 WORK REST low headshake

'Unfortunately, I am unemployed.' (Zeshan 2000b: 151) 
New Zealand Sign Language

INDEX3 ESCAPE AGAIN

slow headshake

'He has run away again!'

New Zealand Sign Language

$\overline{\text { INDEX3 BEAUTIFUL INDEX3 }}^{\text {slow headshake }}$

'How beautiful that is!'

Apart from declaratives, a headshake with non-negative meaning can also occur in interrogatives in several sign languages. In Langue des Signes Québécoise (Canada), this is said to emphasise the question (Dubuisson et al 1991: 117), while in Norsk Tegnspråk (Norway) it is a marker of insecurity or politeness (example 13). Headshakes in questions are also quite frequent in Türk İsaret Dili (Turkey), but their distribution and function has not been investigated.

\author{
Norsk Tegnspråk (Norway) \\ BEFORE SCHOOL WHERE ${ }^{\text {headshake }}$ INDEX2 \\ 'Where did you go to school?' (Vogt-Svendsen 1990: 155)
}

In all these cases, the status of the headshake as part of the grammar of the sign language is either doubtful or has not been investigated. Potential arguments for the non-grammatical status of these headshakes may come from their form, their scope, and their relationship with head gestures used by hearing people in the same culture. For example, in Indo-Pakistani Sign Language, the scope of the slow headshake in the meaning of 'unfortunately' is always the whole sentence and cannot vary. By contrast, grammatical nonmanual markers vary in scope, with some initial, topicalised part of the clause typically outside their scope. The slow headshake thus patterns together with other "adverbial" facial expressions rather than with grammatical nonmanual markers (Zeshan 2000b: $178 \mathrm{ff}$.). In New Zealand, the slow headshake is used in exactly the same contexts in both the hearing culture and the sign language, suggesting that it may be a head gesture rather than a grammatical marker in New Zealand Sign Language. Similarly, speakers of Turkish also use a headshake in the context of questions as a communicative gesture.

\title{
2.3. Scope of negative head movements
}

Apart from their status within the grammatical system of the language, negative head movements also differ across sign languages with respect to their scope. The differences are all the more striking given that, at least as far as headshake 
negation is concerned, the form of the nonmanual signal is so similar crosslinguistically. This section gives a summary of scope regularities associated with negative head movements across sign languages.

Given that negative head movements, in particular the headshake, could in principle combine freely with the manual signs and co-occur with any section of the clause, it would seem quite natural to assume that headshake negation would often be used for constituent negation. This article is mainly concerned with clause negation, where the polarity of the whole clause is negative, whereas constituent negation involves negation of only some part of the clause, for example with a negated adverbial such as 'not today'. To limit the scope of headshake negation to just the constituent that is to be negated seems like an obvious strategy open to sign languages. However, the data demonstrate that in reality, this is very uncommon. As will be detailed in this section, most sign languages place strong constraints on the scope of negative head movements which prevent its use as a device for constituent negation.

To address the more frequent headshake negation first, the most common scope for headshakes is either the whole clause, as in (3) and in (16a), or the whole clause minus any topicalised constituents. The topic may itself be marked with a nonmanual configuration ( $-\mathrm{t}$ ) of its own (example 14), or may be left unmarked (example 15). These two scope possibilities occur in 14 sign languages in the corpus, while 8 sign languages have other scope regularities and for another 16 not enough evidence is available to reach a conclusion on this point. Most sign languages also have other scope possibilities in addition to the two most frequent ones. Those sign languages with more complicated scope regularities will be of particular interest here.

Finnish Sign Language

$\overline{\text { TOMORROW }}^{\mathrm{t}} \overline{\mathrm{CANNOT}}$ 2:VISIT:1 $^{\text {headshake }}$

'Tomorrow, you cannot visit me.' (see Figure 3)

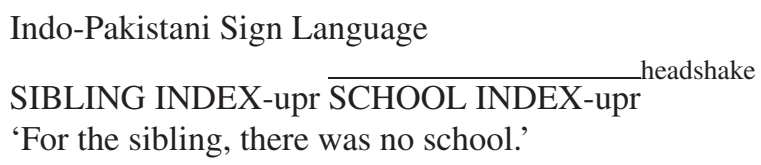

The two frequent patterns have one aspect in common with other scope possibilities: No matter where the headshake begins, it usually has to continue up to the end of the clause. That is, medial headshakes are ruled out in most sign languages. For example, in Langue des Signes Québécoise (Canada), the scope of headshake negation is always from the verb or predicate up to the end of the clause (Berthiaume \& Rinfret 2000: 11ff.). The headshake cannot begin before the verb/predicate and cannot be stopped before the end of the clause (example 16). This has several implications, including the fact that constituent 


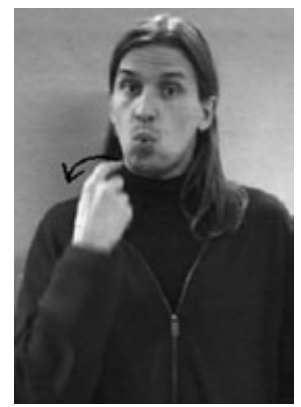

TOMORROW

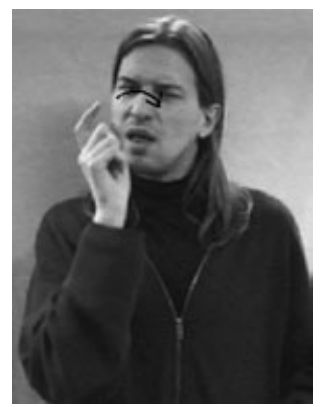

CANNOT

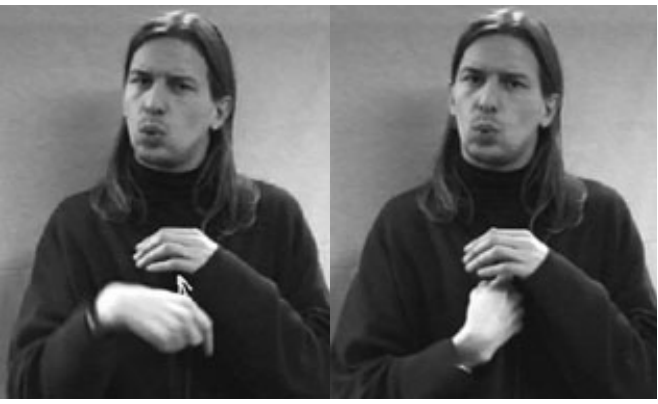

2:VISIT:1

Figure 3. Example 14 (Finnish Sign Language)

negation cannot be expressed through the scope of headshake negation and the fact that subjects do not usually fall under the scope of the negation unless they are shifted to a position after the verb/predicate. The tendency of disallowing nonmanual marking in the middle of a clause is also observed in other clause types such as in questions marked by facial expressions (Zeshan 2004).

Langue des Signes Québécoise (Canada)

a.

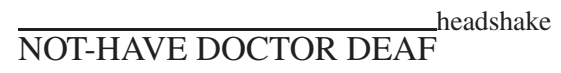

b. * ${ }_{\text {NOT-HAVE }}^{\text {headshake }}$

c. DOCTOR DEAF NOT-HAVE headshake

d. * ${ }_{\text {DOCTOR DEAF NOT-HAVE }}^{\text {headshake }}$

'There is no deaf doctor.' (Berthiaume \& Rinfret 2000: 12) 


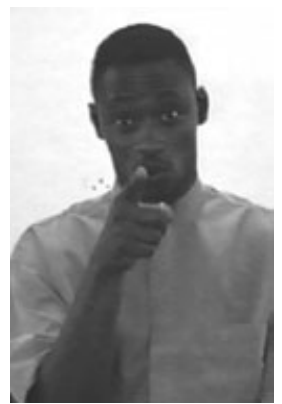

INDEX2

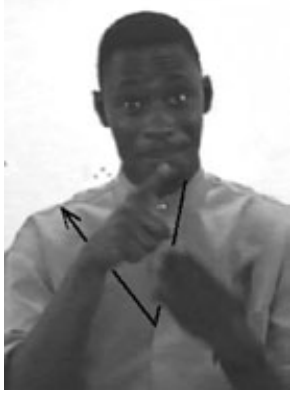

PASS

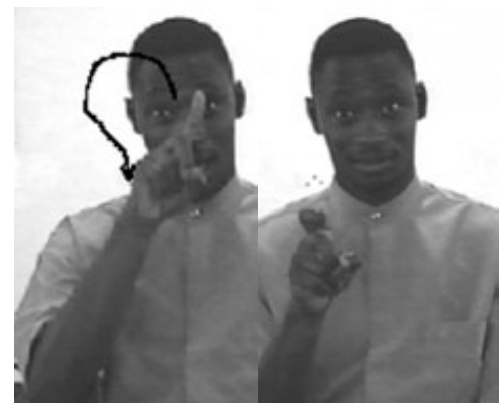

EXAM

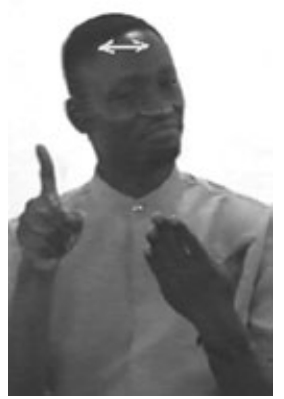

headshake

Figure 4. Example 18 (Ugandan Sign Language)

A structure with the headshake occurring at the end of the clause either by itself or together with a pronoun is also not uncommon and is found in the data in sign languages from Greece (example 5), Ireland (example 17), New Zealand, the UK, Greece, and Uganda (example 18). In Irish Sign Language, this structure seems to be mainly used with a contrastive meaning.

Irish Sign Language

T-E-A INDEX1 $\overline{\mathrm{LIKE}}^{\text {nod }} /$ COFFEE INDEX1 1 headshake

'I like tea, but not coffee.'

\section{Ugandan Sign Language}

$\overline{\text { INDEX2 EXAM PASS }}^{\mathrm{t}}$ headshake

'You won't pass the exam.' (see Figure 4)

Many sign languages also have a frequent construction with headshake negation on a manual negator sign only, or on both the verb/predicate and the following negator sign. This is facilitated by the fact that negator signs are often 
clause-final in sign languages (Section 3.2), so that non-final headshakes can be avoided. Deutsche Gebärdensprache (Germany) seems to be peculiar in this respect, since a headshake scope on the manual negator sign only is disallowed (example 19).

$$
\begin{aligned}
& \text { Deutsche Gebärdensprache (Germany) } \\
& \text { a. MOTHER FLOWER } \overline{\mathrm{BUY}}^{\text {headshake }} \\
& \text { b. MOTHER FLOWER } \overline{\mathrm{BUY}}^{\text {hOT }} \text { headshake } \\
& \text { c. * MOTHER FLOWER BUY } \overline{\mathrm{NOT}}^{\text {headshake }}
\end{aligned}
$$

'The mother does not buy a flower.' (Pfau \& Glück 2000: 11)

Although this is really uncommon, a few sign languages do allow non-final headshakes. In Íslenskt táknmál (Iceland), the headshake can appear on a single constituent, which can be non-final, as in (20). This seems to make it possible for this sign language to use headshake negation as a strategy for constituent negation, although the data are not really conclusive at this point. In Hong Kong Sign Language, the headshake is restricted to the manual negator NOT and/or the verb. If these are non-final, this results in a non-final headshake. However, if a negative facial expression is also used, the facial expression (with spread lips and furrowed brows, see Figure 5) does continue up to the end of the clause (example 21; see also examples 8 and 9 in Section 2.2). It almost seems as if the two constraints - grammatically restricted scope of the headshake and avoidance of a non-final nonmanual marking - are in conflict with each other here. Having the negative facial expression continue up to the end of the clause seems to offer a compromise between the two constraints. The regularities in Hong Kong Sign Language also demonstrate that the scope of a negative head movement and the scope of a negative facial expression can be independent of each other. It seems that this also happens in a number of other sign languages (example 22 is from Lengua de Señas Argentina), but there are currently not enough data to elaborate on this topic.

$$
\text { Íslenskt táknmál (Iceland) }
$$

INDEX-NOT-WANT ${ }^{\text {headshake }}$ GO CINEMA

'He doesn't want to go to the cinema.'

$$
\text { Hong Kong Sign Language }
$$

INDEX3 3 hOT ${ }_{\text {headshake }}^{\text {SWIM KICK-BALL }}$

'He neither swims nor plays football.' 


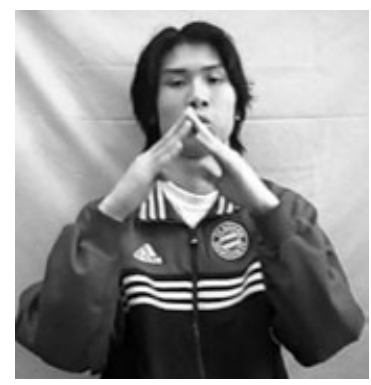

HOUSE

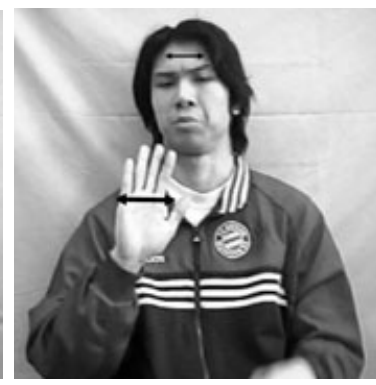

NOT

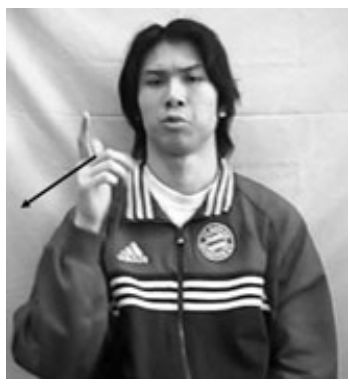

FAR

Figure 5. Headshake and negative facial expression in Hong Kong Sign Language

$$
\begin{aligned}
& \text { Lengua de Señas Argentina } \\
& \text { IF J-O-H-N COME INDEX1 GO CANNOT headshake } \\
& \text { 'If John comes, I cannot go.' (Veinberg 1993: 99) }
\end{aligned}
$$

The scope of the backward head tilt that we find in sign languages of the Eastern Mediterranean is obviously quite different from the headshake. Since this negative marker involves a single head movement, it does not easily spread over more than one sign. In Greek Sign Language, the backward head tilt occurs either on a single sign or clause-finally by itself. For emphatic purposes, it does sometimes spread over the whole clause, in which case the head movement begins with the first sign, is held throughout the clause, and is completed together with the clause-final negation sign (Antzakas 2002). However, this is quite rare. In Türk İşaret Dili (Turkey), the backward head tilt can be repeated, but only if it occurs by itself, as in (23), or if the sign it co-occurs with is also repeated. A repeated head tilt does not occur on individual signs. As in Greek Sign Language, the scope of the head tilt is usually a single sign. However, in one particular environment the head tilt regularly co-occurs with two signs, a predicate and a following negator NOT. This happens when NOT is cliticised to the preceding sign, as in KNOW`NOT in (24).

(23) Türk İşaret Dili (Turkey)

MIX ONE-ONE INDEX1 "speak"-1 SIGN-r —head back _head back

'For me to mix up signing and speaking, that's no good.'

(24) Türk İşaret Dili (Turkey)

INDEX1 SPEAK $\overline{\mathrm{KNOW} N O T}^{\text {head back }}$

'I can't speak.' 
Whenever NOT is cliticised, the backward head tilt that is usually associated with NOT regularly spreads over the entire host-clitic combination. In fact, this is one argument for the status of NOT as a clitic rather than an independent particle in this kind of construction. The negative clitic in Türk İşaret Dili is described in more detail in Section 3.3.

Examples such as (23) and (24) demonstrates that the backward head tilt can be subject to clear-cut grammatical rules with respect to its scope, although the possibilities are naturally rather more restricted than in the case of the negative headshake. As will be detailed in the next section, the backward head tilt is also subject to restrictions as far as its combination with manual negator signs is concerned.

\subsection{Relationship between manual and nonmanual negation}

Since it is most common in sign languages to have a double expression of negation both manually and nonmanually, a question immediately presents itself as to how exactly manual and nonmanual negation combine with each other. The previous sections have already dealt with the frequency of manual and nonmanual negation and with specific nonmanual signals that accompany individual signs in various sign languages. In this section, we will take a closer look at crosslinguistic differences with respect to the compatibility of manual negator signs and nonmanual negative marking focusing on negative head movements. As we will see, it is not at all the case that any negative head movement can be freely combined with any manual negator sign.

Two different kinds of constraints on the combination of manual and nonmanual negation can be observed in the data. In the first instance, the constraint seems to be motivated by the form of the negative signs and head movements involved. In other words, the rules appear to be operating at a phonological level, while the second type of constraint presents no such explanation and can be assumed to operate at a syntactic level.

The backward head tilt is a good example of a constraint that seems to operate at the phonological level in the languages where it occurs, although more data would be needed to confirm this assessment for all languages involved. What is noticeable immediately is that the backward head tilt preferably occurs with signs that involve an upward or backward movement of the hand. Figure 6 shows examples of signs from Greek Sign Language, Türk Işaret Dili (Turkey), and Lughat al-Isharat al-Lubnaniya (Lebanon) that mostly occur in combination with the backward head tilt. The Greek sign involves upward wrist bending of a stationary hand, while the signs from Turkey and from Lebanon move outward from the body in an upward-downward arc. By contrast, signs with a sideways movement strongly tend to occur with the side-to-side headshake (Figure 7). This is not an absolute rule, as counterexamples can be found 


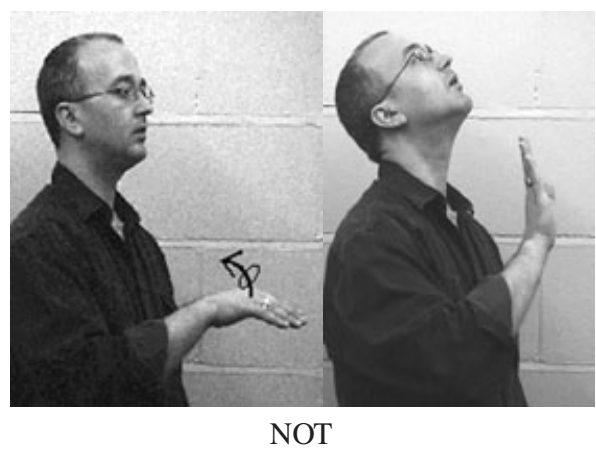

Greek Sign Language

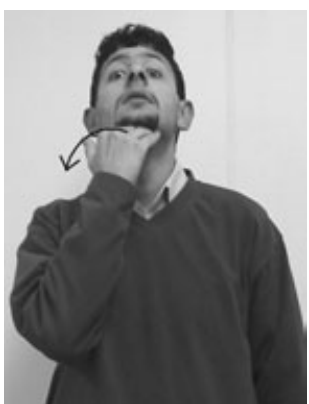

CANNOT

Türk İşaret Dili

(Turkey)

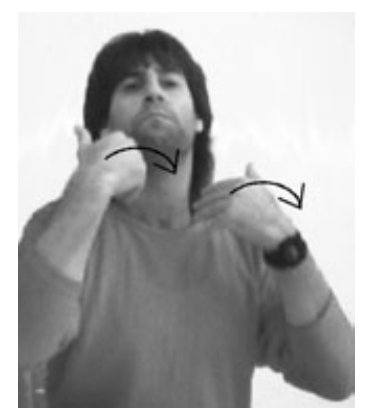

NOT EXIST

Lughat al-Isharat al-Lubnaniya

(Lebanon)

Figure 6. Signs with backward head tilt

quite easily, but the tendency is clearly much too strong to be due to chance. Since no functional difference between the two types of head movements has been found so far, it seems reasonable to assume that this is a kind of formational harmony between the movement of the head and the movement of the hand.

In sign languages where there is no choice between different kinds of head movements, constraints only concern the possibility of individual signs to combine with headshake negation. For instance, the data from Ugandan Sign Language suggest that headshake negation is unlikely to occur with the signs NOTHING (the most common clause negator, also used as a negative existential and as a negative quantifier) and ZERO (used as a negative existential and as a negative quantifier). Only one out of ten examples with these two negators has headshake negation, whereas the headshake occurs freely with other 


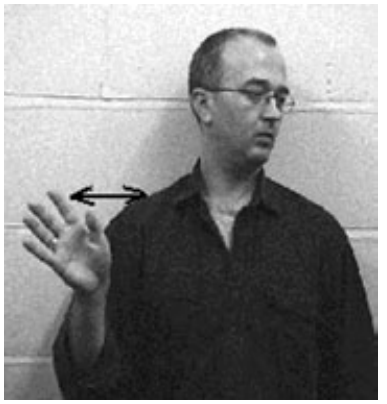

NOT2

Greek Sign Language

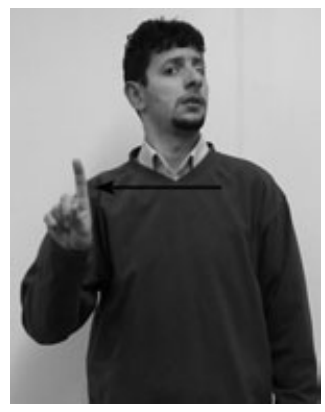

NO

Türk İşaret Dili

Figure 7. Signs with side-to-side headshake

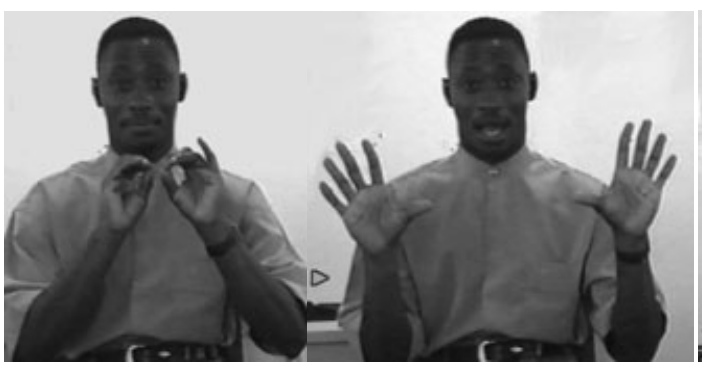

NOTHING

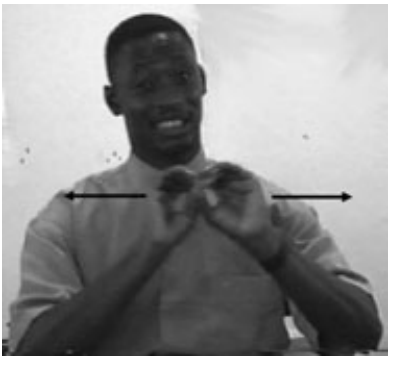

ZERO

Figure 8. Signs without headshake in Ugandan Sign Language

negator signs. Moreover, there are no formational characteristics of NOTHING and ZERO that would suggest that they might be incompatible with headshake negation (see Figure 8), so that this seems to be an arbitrary constraint in this particular sign language.

In Hong Kong Sign Language, the headshake regularly co-occurs with the basic clause negator NOT. However, other clause negators can have reduced nonmanual negative marking and are usually not accompanied by headshake negation. Instead, nonmanual negation is restricted to a negative facial expression, typically involving lowered eyebrows and spread lips, as seen in Figure 5 , which can be more or less strongly articulated. In all available examples, the scope of the negative facial expression is restricted to the clause-final negator sign only (examples 25 and 26). 
INDEX1 MONEY NOT-HAVE ${ }^{\text {face-neg }}$

'I have no money.'

\author{
Hong Kong Sign Language \\ INDEX3 BUY CAR $\overline{\text { WILL-NOT }}^{\text {face-neg }}$ \\ 'He will not buy a car.'
}

The Scandinavian sign languages in Sweden and Norway present a different kind of constraint. While headshake negation is very common both with and without an accompanying manual negative sign, there is one environment where headshake-only negation is disallowed. As Bergman (1995) notes, with signs such as CAN and NEED, which she calls "auxiliaries", a manual negator must be present in the clause and headshake-only negation is ungrammatical (example 27). In addition, these signs have morphologically complex negative forms with an attached negative morpheme that seems to be a strongly reduced form of NOT. Both CAN NOT (as two signs) and CAN+NOT (as one complex sign) are possible, but CAN plus headshake negation is disallowed.

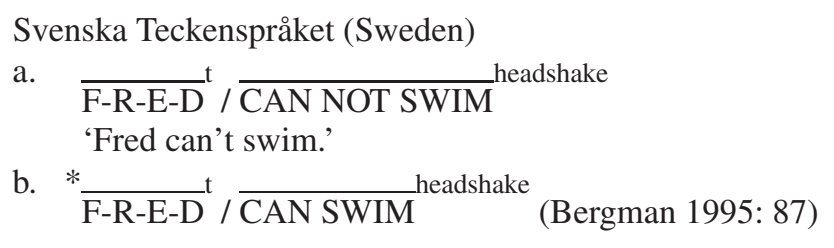

a.

$\overline{\text { F-R-E-D }}^{\mathrm{t}} / \overline{\text { CAN NOT SWIM }}$ 'Fred can't swim.'
b. *
$\overline{\text { F-R-E-D }}^{\mathrm{t}} / \overline{\mathrm{CAN} \mathrm{SWIM}}^{\text {headshake (Bergman 1995: 87) }}$

* ${ }^{\mathrm{t}}$ headshake

There clearly is a link between the obligatory use of a manual negator in these cases and the existence of morphologically complex negatives for the same signs: "The obligatory use of NOT in sentences with auxiliaries may be the reason why auxiliaries have developed morphologically negated forms" (Bergman 1995: 87). In cases where the negator and the predicate are closely linked, it seems that headshake negation is less central. This is also in line with the observation that headshake negation is often omitted in sentences with underived, inherently negative predicates such as KNOW-NOT (Bergman 1995: 93).

In many sign languages, there is thus an intricate interplay between manual and nonmanual negation that manifests itself at various levels of structure, from the compatibility of manual and nonmanual negators to the scope of nonmanual markers and questions of relative frequency. In the following sections, we will be taking a closer look at negator signs and their grammatical characteristics in the sign languages in our data. 


\section{Manual clause negation}

This section describes various manual signs that are used as clause negators across sign languages. Sign languages overwhelmingly use negative particles, but the paradigms of negatives found across sign languages differ substantially (Section 3.1), and syntactic patterns show some variation as well (Section 3.2). On the other hand, the forms of negative signs can be strikingly similar across genetically and geographically unrelated sign languages. To a lesser extent, sign languages also make use of morphological means of negation with a negative morpheme incorporated into the predicate, in which case the result is usually an irregular negative form (Section 3.3).

Throughout this section, I distinguish between BASIC CLAUSE NEGATORS and OTHER CLAUSE NEGATORS. The function of a basic clause negator is only to reverse the polarity of the clause, and it can thus be thought of as the most neutral way of negating a clause. By contrast, other clause negators have more specific meanings and functions in addition to negation, for example an aspectual value (negative completive 'not yet'), an emphatic function ('not at all'), or a modal meaning ('cannot').

\subsection{Paradigms of clause negators}

In spoken languages, morphological negation by way of affixing and the use of an uninflected negative particle are by far the most common ways of negating a clause. In a sample of 240 languages, Dahl (1979: 84) found 108 languages with morphological negation and 99 languages with uninflected negative particles. Sign languages show a strikingly different pattern. All sign languages in our data use uninflected negative particles, while no sign language uses morphological negation as a general negative strategy. Where morphological means of negation do exist, they never cover the whole range of predicates, but always apply to a limited number of signs only. Differences in negation strategies between sign languages and spoken languages, including the very different role of prosody in negation, are summarised in Section 4.

Almost all sign languages in the data have a negative particle that conveys basic clause negation in our sense. In some cases, however, it seems as though nonmanual negation should really be considered as the most frequent and/or the most unmarked way of negating a clause. Scandinavian sign languages have been discussed in this regard in Section 2.2, and in Langue des Signes Québécoise (Canada), manual negator signs are similarly said to be rare, while the headshake is described as "le principal moyen de nier" (Berthiaume \& Rinfret 2000: 3). Some sign languages have a negative particle that subsumes both the function of basic clause negation and another, more specific function. In Ugandan Sign Language, the sign NOTHING appears most frequently and in the widest variety of contexts, including those that would qualify as instances 
of basic clause negation. However, NOTHING also functions as a negative existential and as a negative quantifier, so that basic clause negation seems to be a sub-function of the sign NOTHING. For Tanzania Sign Language, no clear candidate for a basic clause negator could be identified from the data, and it is not clear whether the headshake assumes this function, or whether basic clause negation is included as a sub-function of the negative existential. As will be detailed in this section, negative existentials do seem to have a prominent status in many sign languages.

As far as other negator signs are concerned, a wide variety of functions is covered in the sign languages in the data. Although the negators are all similar in that they are independent signs rather than affixes, each sign language has its own paradigm of negators that differs from other sign languages in both the number of negatives and the choice of negative category. Crosslinguistically, some types of negatives are much more common than others. Table 3 gives an overview of negative categories and the number of sign languages that they occur in. The list includes the following items:

- Negative existentials ('not exist', 'there is/are no'). In most cases, there is an intimate connection between existential and possessive functions, that is, 'not exist' and 'not have' are expressed in the same way. This is also typical of many spoken languages, in particular creoles (Sebba 1997: 174).

- Negative modals. This category covers a variety of modal meanings such as 'cannot', 'need not', 'will not', 'may not', and 'should not'. In the latter meanings, a negative modal is sometimes difficult to distinguish from a negative imperative. 'Cannot' is by far the most common negative modal.

- Negative completive ('not yet'). This is by far the most common negative with an aspectual function. It usually contrasts with a positive completive aspect particle.

- Negative imperative ('don't!'). Although this is a pragmatically "strong” category, it is less common across sign languages than other negators. The function of negative commands may be subsumed under or combined with other negative functions, in particular negative existentials, emphatic negatives, or negative modals.

- Emphatic negative ('not at all', 'really not', 'absolutely not'). These negators convey a stronger kind of negation. Most sign languages can achieve this effect by varying nonmanual features co-occurring with a basic clause negator. The number of sign languages that have separate emphatic negator signs (sometimes more than one) is comparatively smaller.

- Negative interjection. This category covers all signs that occur by themselves as one-word utterances. There is a wide variety of meanings such as simple negative responses ('no'), expressions of disavowel ('not me', 'have never done/seen'), emphatic interjections ('not at all!'), and meta-comments on a situation ('it's nothing', 'never mind'). 
Table 3. Frequency of negative categories across sign languages

\begin{tabular}{lc}
\hline NEGATIVE CATEGORY & Number of occurrences \\
\hline negative existential & 29 \\
negative modal & 27 \\
negative completive & 23 \\
negative imperative & 17 \\
emphatic negative & 7 \\
negative interjection & 7 \\
contrastive negative & 3 \\
\hline
\end{tabular}

- Contrastive negative. This is a rare category where a separate particle is used to convey a negative meaning in contrast with something else, like saying 'this is not the case, in contrast to what has been said/has been implied/usually happens/is generally acknowledged'. The contrast may be made explicitly or may be implied.

It may be noted that even for those negative categories that are very frequent, the number of occurrences given in Table 3 is substantially less than the total number of 38 sign languages in the data. This is because for a number of sign languages, no information or insufficient information was available on this point. In other cases, the function of a negative particle could not be established, so that it could not be assigned to any of the categories in the table. However, the table does demonstrate the relative frequency of negative categories across sign languages, although it fails to record all negatives in all 38 sign languages.

Within the paradigm of negative particles, some sign languages make interesting grammatical distinctions that are worth looking at in more detail. First of all, sign languages seem to be particularly rich in both positive and negative existential particles, which are often suppletive forms (Section 3.3). In Nihon Shuwa, there is an animate/inanimate distinction with existentials (cf. Japanese $i r u$ versus $a r u$ ). The sign in Figure 9a is only used with animates and also means 'live at (a place)' in addition to the existential meaning. The sign in Figure $9 \mathrm{~b}$ is mainly used as an existential with inanimates, but can refer to animates occasionally, in particular in combination with kinship terms. In this case, there is also an interesting semantic difference between a possessive and an existential reading, as illustrated in (28).

Nihon Shuwa (Japan)

a. ${ }_{\text {OLDER-BROTHER EXIST(inanimate): } 3} \mathrm{y} / \mathrm{n}$

'Does he have an older brother?' 


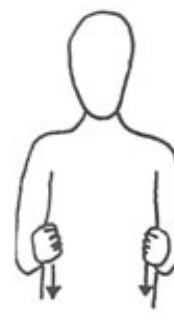

(a)

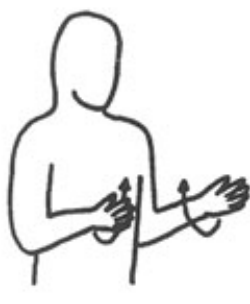

(c)

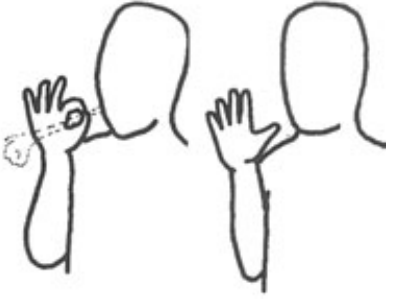

(d)

Figure 9. Positive and negative existentials in Nihon Shuwa (Japan)

b.

OLDER-BROTHER EXIST(animate): 3 $y / n$

'Is his older brother around?' (Susan Fischer, pers. comm.)

These existentials cannot be combined with negation, so that corresponding negatives have to be used. For the negation of an animate existential, the sign in Figure 9c, which also seems to function as the basic clause negator, is almost always used. For the negation of inanimate existentials, there is more freedom in the choice of negators. The sign in Figure 9d is probably a negative existential and could be used in a context referring to inanimates.

Lugha ya Alama Tanzania also has two negative existentials, but the distinction here is of a different nature (CHAVITA 1993: 239, 243, 244). The sign HAKUNA 'no, not so, there isn't' (Figure 10a) seems to be a neutral negative existential, whereas the sign HAKUNA/HAPANA 'no/not so/there is none' (Figure 10b) is apparently a more emphatic existential. Both are used as negative existentials, but the stronger form HAKUNA/HAPANA is also used as a negative imperative and for emphatic negation in addition to its existential function. In the positive, there is no such distinction, the only existential being the sign IPO 'it is (there), it exists' (Figure 10c). The negative existentials are also used to express possession.

Moving away from existentials to some of the other categories in Table 3, we also note the pervasiveness of completive aspect particles in sign languages. This holds for both positive and negative completive and is in marked contrast with the general absence of a category of grammatical tense in sign languages. Sign languages generally use time lexemes at a discourse level to locate an utterance in time, but do have more or less extensive systems of aspect and aktionsart. While categories such as iterative, continuative, and the like, are often marked by modifying the movement pattern of a predicate sign, completive aspect is regularly signalled by an independent particle that may be homonymous 


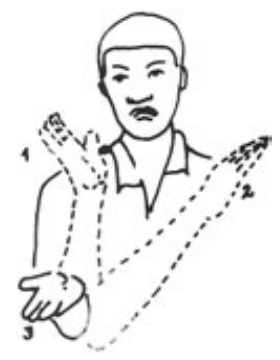

(a)

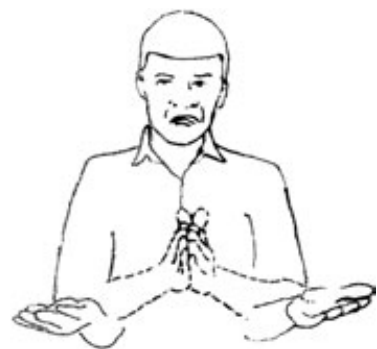

(b)

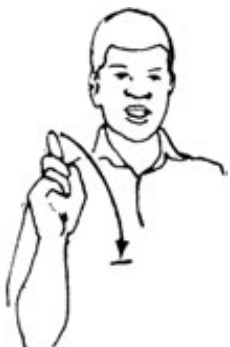

(c)

Figure 10. Positive and negative existentials in Lugha ya Alama Tanzania

with a lexical predicate 'finish'. ${ }^{4}$ The corresponding negatives are again often suppletive forms. Aspectual distinctions sometimes go beyond the marking of completive aspect. For example, Lingua Italiana dei Segni (Italy) and Deutsche Gebärdensprache (Germany) both have two negative particles in the aspectual domain, contrasting 'not yet' with 'not any more'. However, this is quite rare across the whole range of sign languages in our data.

As was mentioned before, contrastive negation seems to be rare across sign languages. However, it is also one of the more elusive negative categories, so it is quite possible that there may be other cases that have not been recognised. Differences between neutral and contrastive negation can be quite subtle and difficult to recognise, as (29) and (30) from Indo-Pakistani Sign Language demonstrate.

Indo-Pakistani Sign Language

a. PROBLEM NEG(neutral)

'There is no problem.'

b. PROBLEM NEG(contrastive)

'There is no problem.' (contrary to what you may be expecting, contrary to what usually happens, etc.)

Indo-Pakistani Sign Language

a. CITY GOOD NEG(neutral)

'Cities aren't nice (places).'

b. VILLAGE GOOD / CITY NEG(contrastive).

'Villages are nice, but cities are not.'

4. Türk İşaret Dili (Turkey) seems to allow for an exception, expressing completive aspect by modifying the movement pattern of a sign (Zeshan 2003). In Indo-Pakistani Sign Language, the completive aspect particle is distinct from the lexical predicate 'finish'. 
The only difference between (29a) and (29b) is the signer's implication in (29b) that there is supposed to be some problem. For example, (29b) would be appropriate in a context with a preceding question 'Is there a problem?', thus expressing a contrast with the content of the question. However, the contrast may be entirely implicit and based only on assumptions on the part of the signer such as represented in the addition to the translation ('contrary to ...'). In (30b), the use of the contrastive negative is licensed by the contrast with the preceding clause (expressed in the translation as 'but'), while (30a) has no such implication and therefore uses the neutral negative particle.

On a larger scale, negators in sign language may interact with other domains in the grammar. An interesting example of this is provided by Israeli Sign Language. This sign language has a rather large set of negative particles, including a basic clause negator, three negative imperatives, two negative existentials NEG-EXIST(1) and NEX-EXIST(2), negative completive (NEGCOMPL), negative past (NEG-PAST), and emphatic negation (Meir 2002). Some of the negators interact with lexical categories, so that NEG-COMPL and NEG-PAST co-occur with verbs, NEG-EXIST(1) and NEG-EXIST(2) cooccur with nouns, and adjectives and predicative nouns co-occur with the basic negator NOT (example 31). In fact, the distribution of the negators is itself a crucial argument for the establishment of these three word classes in Israeli Sign Language in the first place, since arguments used to establish word classes in other sign languages do not work across the board for this language.

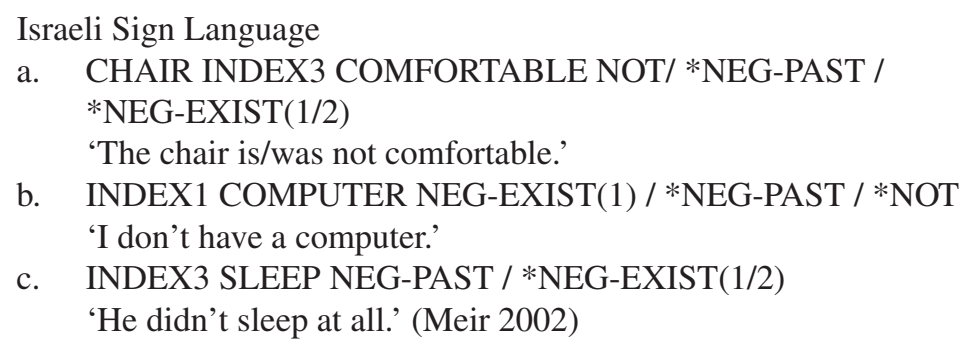

A final point to note about paradigms of clause negators is the striking recurrence of particular forms in the negator signs. In particular, four forms are frequent across sign languages irrespective of genetic or geographical association. These formational characteristics can occur in signs individually or in combination with each other and include (i) repeated side-to-side movement or wrist twisting, (ii) single sideways movement, (iii) a hand orientation with the palm facing outward, and (iv) a round ' $\mathrm{O}$ '-type handshape.

Repeated wrist twisting often creates a visual impression that is very similar to repeated side-to-side movement, which is why the two patterns are grouped together. Repeated movement patterns, especially those with the hand alternating between two different states, are also common in interrogatives (Zeshan 


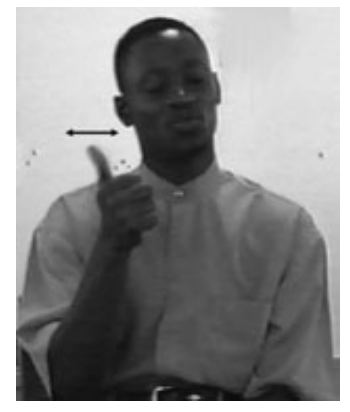

NOT YET

Figure 11. Ugandan Sign Language

2004). The second movement pattern that often occurs in negatives is a single sideways movement in either one- or two-handed signs, in the latter case with both hands moving outwards from the centre. This pattern is quite often associated with negative imperatives or, to a lesser extent, strong/emphatic negatives, and the movement may accordingly be produced with more or less emphasis mirroring the pragmatic force of the negation. A hand orientation with the palm facing forward and away from the body is commonly found with either of the two movement patterns, and the finger tips typically point upwards. Finally, 'O'-like handshapes are particularly common with negative existentials and negative quantifiers. This may be due to influence from the writing system in those cultures where the number 'zero' is represented by an ' $\mathrm{O}$ '-like shape. The handshape may combine with one of the two movement patterns and/or the characteristics palm orientation in individual signs. Sometimes the movement pattern is itself circular, creating a kind of doubly instantiated 'zero'-shape. Table 4 summarises some possibilities of combination for these formational characteristics of negative signs, together with examples for each case.

All forms noted here obviously have an iconic motivation of some sort, although it is not easy to pin down in each case what exactly the motivation consists in. Iconicity can in fact be quite abstract, but it would be beyond the scope of this article to go into details. In this context, it may also be noted that negative particles in sign languages are often either the same as or related to negative gestures used in the surrounding hearing culture, which may in turn be iconically motivated. Signs in a sign language, being part of a grammatical system, obviously function quite differently from gestures, but this is another issue that we cannot go into at this point. 
Table 4. Common formational characteristics of negatives ${ }^{a}$

\begin{tabular}{|c|c|c|}
\hline $\begin{array}{l}\text { FORMATIONAL } \\
\text { FEATURES }\end{array}$ & les & Figure \\
\hline $\begin{array}{l}\text { repeated twist } \\
\text { of the wrist }\end{array}$ & $\begin{array}{l}\text { Indo-Pakistani Sign Language NOT (same form for basic } \\
\text { clause negator in Thai Sign Language); } \\
\text { Ugandan Sign Language NOT-YET (same form and function } \\
\text { in Lugha ya Alama Tanzania and in Kenyan Sign Language) }\end{array}$ & Fig. 11 \\
\hline $\begin{array}{l}\text { side-to-side } \\
\text { movement with } \\
\text { outward palm } \\
\text { orientation }\end{array}$ & $\begin{array}{l}\text { Greek Sign Language NOT (same form in Türk İşaret Dili, } \\
\text { Hong Kong Sign Language, Chinese Sign Language and } \\
\text { Kata Kolok (Bali), in Finnish Sign Language and Thai Sign } \\
\text { Language for negative imperative, in Indo-Pakistani Sign } \\
\text { Language for contrastive negation) }\end{array}$ & Fig. $7^{\mathrm{b}}$ \\
\hline $\begin{array}{l}\text { single sideways } \\
\text { movement }\end{array}$ & $\begin{array}{l}\text { Türk İşaret Dili NO (same form in Israeli Sign Language } \\
\text { and Língua de Sinais Brasileira for negative imperative, in } \\
\text { Finnish Sign Language for MAY-NOT, in Lingua Italiana dei } \\
\text { Segni for interjection NO, in Vlaamse Gebarentaal for basic } \\
\text { clause negator NOT); } \\
\text { Finnish Sign Language emphatic negation (same form in } \\
\text { Swedish Sign Language for negative modal/future, American } \\
\text { Sign Language for negation in formal contexts, and British } \\
\text { Sign Language) }\end{array}$ & Fig. 12 \\
\hline $\begin{array}{l}\text { O-handshape } \\
\text { with single } \\
\text { movement }\end{array}$ & $\begin{array}{l}\text { Ugandan Sign Language ZERO (same form in Thai Sign Lan- } \\
\text { guage variant of NOTHING, American Sign Language NONE, } \\
\text { similar form with forward movement in Finnish Sign Lan- } \\
\text { guage); } \\
\text { Ugandan Sign Language NOTHING (similar form with 'open } \\
\text { O' handshape in Nihon Shuwa for negative existential) }\end{array}$ & Fig. 8 \\
\hline $\begin{array}{l}\text { side-to-side } \\
\text { movement with } \\
\text { outward palm } \\
\text { orientation and } \\
\text { O-handshape }\end{array}$ & $\begin{array}{l}\text { Hong Kong Sign Language NOT-HAVE (same form in Chi- } \\
\text { nese Sign Language, New Zealand Sign Language NOTHING, } \\
\text { Lingua Italiana dei Segni NOT-YET, American Sign Lan- } \\
\text { guage IT'S-NOTHING) }\end{array}$ & Fig. 13 \\
\hline $\begin{array}{l}\text { O-handshape } \\
\text { with circular } \\
\text { movement }\end{array}$ & $\begin{array}{l}\text { Indo-Pakistani Sign Language negative existential (same } \\
\text { form in Vlaamse Gebarentaal for interjection NONE-AT-ALL } \\
\text { and Thai Sign Language, with 'closed O' handshape, for } \\
\text { NOTHING) }\end{array}$ & Fig. 14 \\
\hline
\end{tabular}

a Data from co-researchers and from Suwanarat \& Reilly (1986), CHAVITA (1993), Akach (1991), Radutzky (1992), Bergman (1995), Baker-Shenk \& Cokely (1996), Sutton-Spence \& Woll (1999), Moody et al. (1983), Yang \& Fischer (2002).

b A very similar form, but with only the index finger extended, exists in Israeli Sign Language, Lengua de Señas Española, Langue des Signes Française, Lingua Italiana dei Segni, New Zealand Sign Language, Ugandan Sign Language, Indo-Pakistani Sign Language, Lughat alIsharat al-Lubnaniya, and Russian Sign Language. 


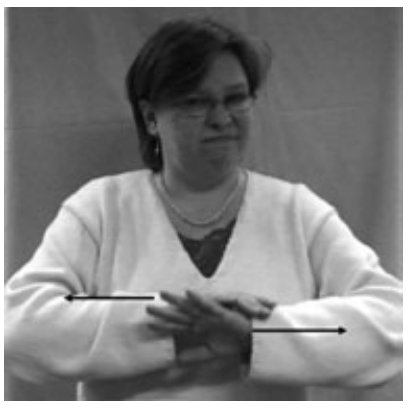

NOT-AT-ALL

Figure 12. Finnish Sign Language

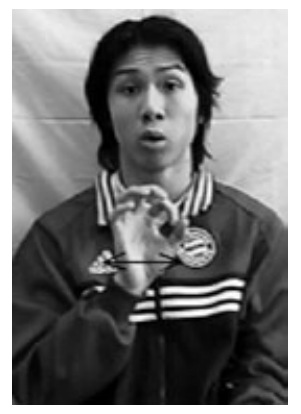

NOT-HAVE

Figure 13. Hong Kong Sign Language

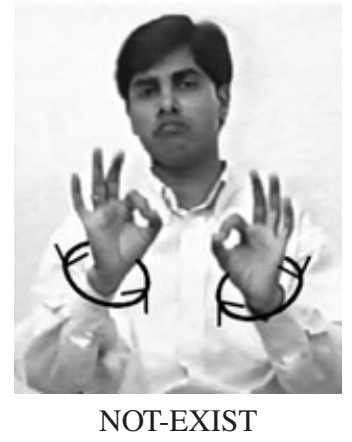

Figure 14. Indo-Pakistani Sign Language 


\subsection{Syntax of clause negators}

Typological studies on spoken languages indicate a strong tendency for negative particles to occur in pre-verbal position (Dahl 1979: 93). Only verb-final languages allow for either pre-verbal or post-verbal placement equally, while all other word order types strongly favour pre-verbal negatives (Payne 1985: 224). For the great majority of sign languages in our data, basic word order has not been clearly established. However, it is clear that independent of word order typology, there is a striking preference for post-predicate or clause-final position of negatives across sign languages. Of the 27 sign languages for which there is information on this point, all allow clause-final position of negative particles. ${ }^{5}$ In some cases, this is the only acceptable position. For example, Indo-Pakistani Sign Language has very strict predicate-final word order with an additional clause-final slot for functional particles marking clause types. All negative particles occupy the clause-final slot, and any other placement of the negative is ungrammatical (example 32).

$$
\begin{aligned}
& \text { Indo-Pakistani Sign Language } \\
& \text { a. } \\
& \text { bOOK INDEX1 TAKE NOT } \\
& \text { b. } \text { *BOOK INDEX1 NOT TAKE } \\
& \text { c. *NOT TAKE BOOK INDEX1 } \\
& \text { 'I don't/didn't take a book/books.' }
\end{aligned}
$$

In comparison with the clause-final position, pre-predicate position is considerably less common and only occurs in 15 sign languages. Interestingly, these are almost exclusively European sign languages and their derivatives in Australasia and the Americas. ${ }^{6}$ By contrast, sign languages that allow only clause-final position for negators are predominantly non-Western, although there are a few cases from Europe as well. For a minority of nine sign languages in the data, there is an additional construction with doubling of the negative particle in both pre-predicate and clause-final position (examples 33 and 34). This construction is particularly interesting in that it amounts to a triple marking of negation, with two negative particles and nonmanual negation. While this doubling pattern is not uncommon across sign languages, the combination of two different manual negatives appears to be very rare, with almost no attested examples in the data.

5. Since a number of examples in the data have a word order with the predicate in final position, it is sometimes difficult or impossible to decide whether a negative particle in a given utterance is in post-predicate or in clause-final position. However, the distinction between post-predicate and clause-final position is not central to the discussion in this section, since the main point is that pre-predicate position is comparatively rare.

6. Most known sign languages in these areas are historically related to European sign languages (cf. Zeshan, forthcoming, about relationships between sign languages). 
What makes the preference for post-placement of the negative even more conspicuous in sign languages is the fact that in all cases of morphological negation where a negative morpheme is attached to a predicate in sequence, the negative appears after the predicate. In spoken languages, typological studies have found a preference for negative prefixes (Payne 1985: 224, Whaley 1997: 229). By contrast, the sign languages in our data exclusively use suffixes and enclitics. Most sign languages have at least some degree of morphological negation, as discussed in Section 3.3, but there is not a single case of a bound negative morpheme in pre-predicate position. Moreover, even in sign languages that do allow negative particles in pre-predicate position, this is never the only option. All these points taken together make for a very strong case for postplacement of negators in sign languages, and I will briefly return to the issue of this and other differences between signed and spoken languages in Section 4.

In sign languages with more than one possible position for the negative, the choice of position sometimes depends on which negative is involved. For example, Hong Kong Sign Language allows for the basic negator NOT to occur in pre-predicate position, while other negators are clause-final. Negative existentials occur either before or after the negated entity. The single most interesting observation in our data, however, concerns differences in meaning related to differences in negator placement. This is observed in the Swedish and Norwegian sign languages. In Svenska Teckenspråket (Sweden), the basic clause negator appears before non-verbal predicates, but after verbal predicates (examples 35 and 36). ${ }^{7}$ With predicates that can have both an active and a stative interpretation, the placement of the negator indicates which reading is intended (example 37).

7. The "non-verbal" category includes adjectival and nominal predicates, but also some stative intransitive verbs (Bergman 1995: 88). 
Svenska Teckenspråket (Sweden)

INDEX1 KNOW NOT

'We don't know.'

Svenska Teckenspråket (Sweden)

INDEX1 NOT RICH

'I am not rich.'

(37) Svenska Teckenspråket (Sweden)
a.
$\overline{\mathrm{K}-\mathrm{A}-\mathrm{L}-\mathrm{L}-\mathrm{E}}^{\mathrm{t}} \overline{\mathrm{ACCEPT} \text { NOT }}^{\mathrm{h}}$
'Kalle did not accept it.'
b. $\overline{\mathrm{K}-\mathrm{A}-\mathrm{L}-\mathrm{L}-\mathrm{E}}^{\mathrm{t}} \overline{\text { NOT ACCEPT }}^{\text {headshake }}$
'Kalle was not accepted.' (Bergman 1995: 87-88)

Norsk Tegnspråk has a very similar distinction, but in addition, changing the position of the negator can make a difference between a possessive reading and a reading with clause negation in an otherwise identical sentence (example 38).

Norsk Tegnspråk (Norway)
a. WE-TWO CHILDREN NOT headshake
'We do not have any children.'

b. ${ }_{\text {WE-TWO NOT CHILDREN }}^{\text {headshe }}$

'We are not children.' (Vogt-Svendsen 2000)

\subsection{Irregular negatives}

Having covered nonmanual negation and independent negative particles, this section deals with a third type of negative marking where negation is part of the predicate in one way or another. Some of the forms discussed here are equivalent or similar to familiar types of morphological negation by affixing in spoken languages. However, in sign languages the number of items that allow morphological negation is usually very small, whereas spoken languages typically use affixing as a general negation strategy. The number of such negatives in sign languages can range from a single item to a maximum of about 25 items (Zeshan, forthcoming). Because of this restricted distribution, negative forms of individual signs are called IRREGULAR NEGATIVES here. Table 5 provides an overview of the various types of irregular negatives that occur in sign languages. The examples given in the lower half of the table will be discussed in this section.

The basic first distinction to be made here is between negative suppletion and morphological negation of various sub-types. Negative suppletion means that a 


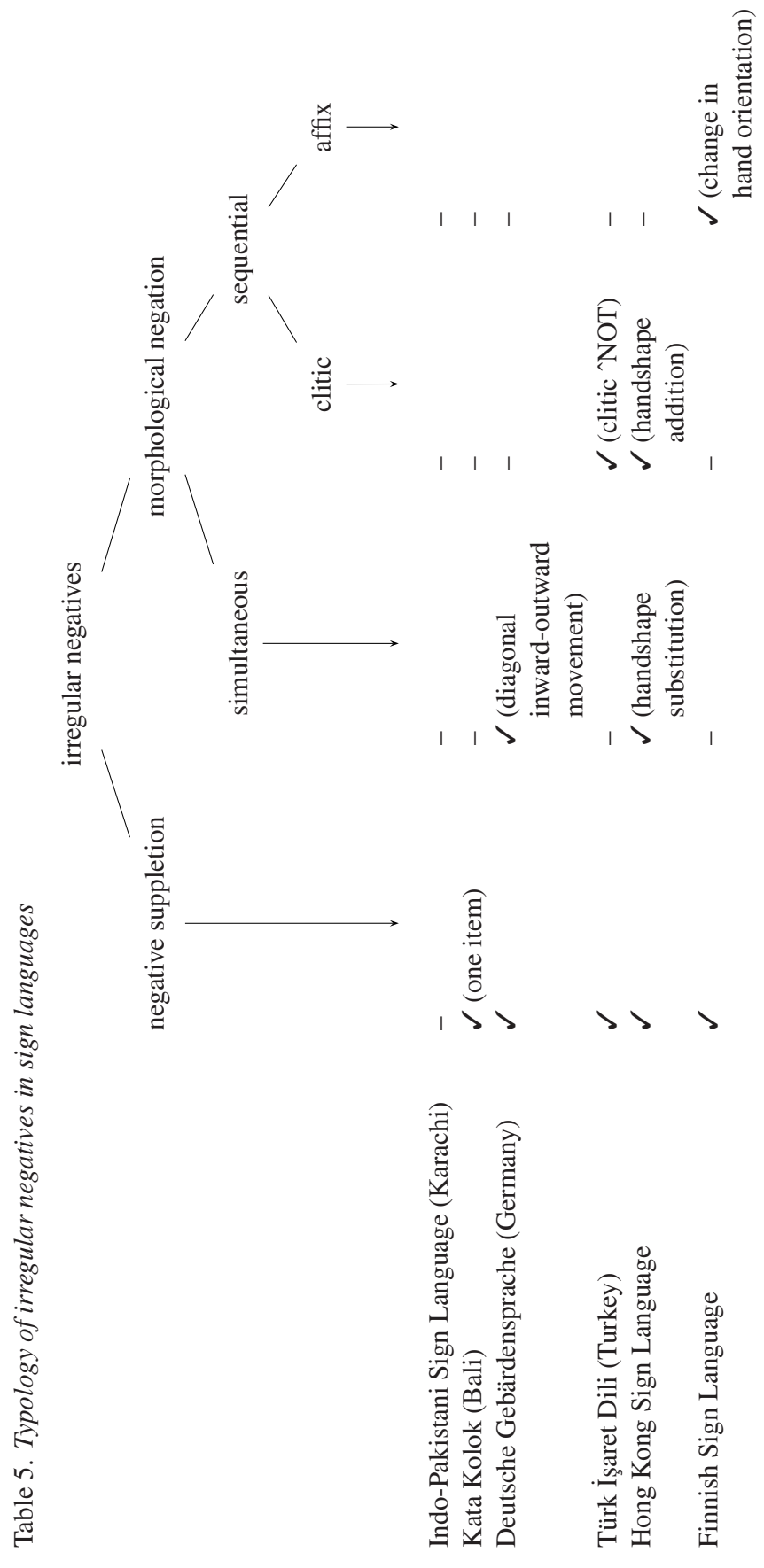




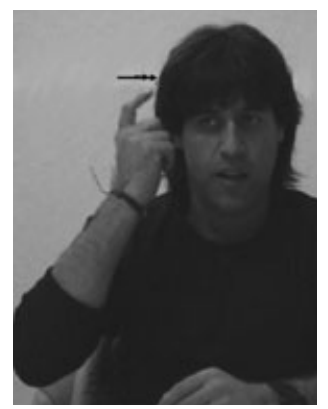

KNOW

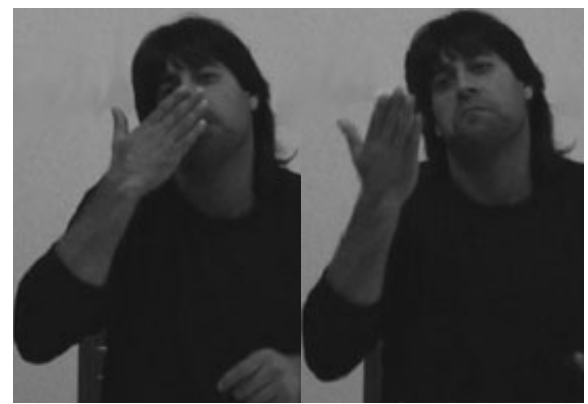

NOT-KNOW

Figure 15. Suppletive negative Lughat in al-Isharat al-Lubnaniya (Lebanon)

positive form and a corresponding negative form are entirely different and cannot be related to each other by any morphological process. Consequently, the suppletive negatives typically have no overt morphological marking for negation. This is common in spoken languages as well as in the sign languages in our data. For example, Turkish positive existential is var, but its negative counterpart is yok, a totally different, unrelated form. Not surprisingly, negative suppletion is limited to a few signs in each language, but is at the same time very widespread across languages. Only one sign language variety in the data, the Karachi dialect of Indo-Pakistani Sign Language, has no suppletive negatives at all. In fact, this dialect has no irregular negation whatsoever and is thus unique among the languages in the data. The village sign language Kata Kolok (Bali, see Branson et al. 1996) has a single suppletive negative for completive aspect ('not yet'), but no other irregular negatives whatsoever (Gede Marsaja, pers. comm.). Similarly, Indian dialects of Indo-Pakistani Sign Language, as well as Lengua de Señas Española (Spain), have only a single irregular negative, which is a suppletive form for the negative existential. Once more, the status of existentials stands out as peculiar in sign languages.

It is not only clause negators (existentials, modals, completives, and so on) that can have suppletive negatives. There are also a number of lexical predicates to which negative suppletion regularly applies in various sign languages. Figures 15 and 16 show examples from Lughat al-Isharat al-Lubnaniya (Lebanon; KNOW and NOT-KNOW) and from Russian Sign Language (WANT and NOTWANT).

As far as morphological negation is concerned, two basic sub-types with quite different properties can be distinguished, involving simultaneous morphology and sequential morphology respectively. In the simultaneous type, negation is marked by a change in one of the formational aspects of the sign. 


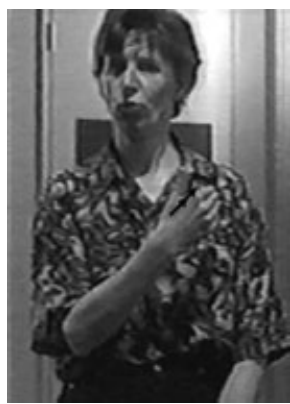

WANT

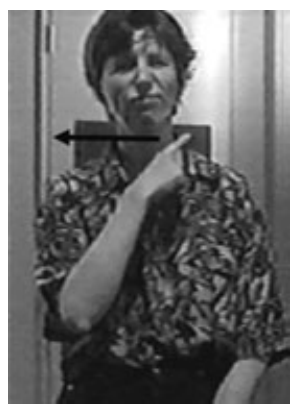

NOT-WANT

Figure 16. Suppletive negative in Russian Sign Language

This may concern the movement pattern or, less commonly, the handshape. Deutsche Gebärdensprache (Germany) has a set of eight signs that form a negative by modifying the movement to constitute a downward and diagonal inward-outward pattern (see Figure 17, with an equivalent form from Russian Sign Language). The movement pattern is clearly a negative morpheme, but it is rather unusual in that it co-occurs simultaneously with the sign as a whole. Therefore, the question whether the negative is a prefix or a suffix becomes meaningless. Instead, this process is roughly comparable to internal morphological processes in spoken languages, such as ablaut. In some East Asian sign languages (China, Hong Kong), a handshape change commonly derives negatives through substitution of a sign's handshape with a "negative" handshape (with only the little finger extended). The handshape change can either be added at the end of the sign, or, in the simultaneous type, occur throughout the sign (cf. Yang \& Fischer 2002). Figure 18 shows an example for each type from Hong Kong Sign Language. By itself, the negative handshape means 'bad', but in irregular negatives, it loses its literal meaning and becomes a negative morpheme.

The sequential type of morphological negation in sign languages is more comparable to sequential morphology in spoken languages. That is, the negative morpheme forms a unit with the predicate sign in a clearly identifiable sequence, with the negative morpheme always appearing after the predicate. The negative morpheme can either be a clitic or an affix, thus resulting in two subtypes. The distinction between a clitic and an affix is itself not clear-cut because the question is basically one of degree, the association between clitic and host being less close than the association between affix and word stem. Moreover, the study of this kind of sequential morphology is itself a very recent undertaking in sign language research, with almost no previous literature to draw on. 


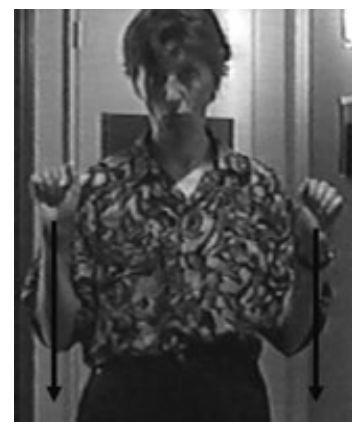

CAN

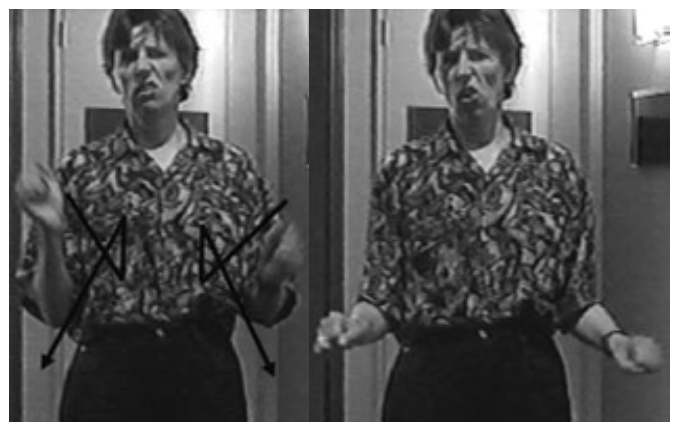

CANNOT

Figure 17. Simultaneous movement modification for negation (Russian Sign Language)

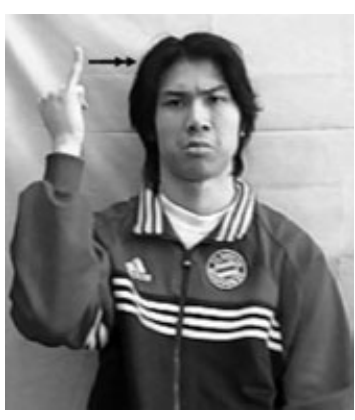

NOT-KNOW

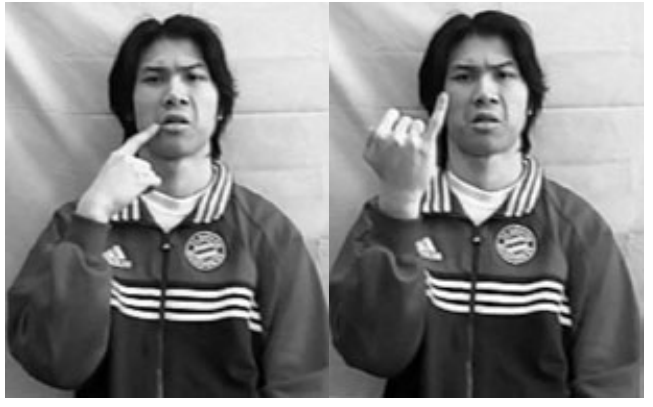

TASTELESS

Figure 18. Negative handshape in Hong Kong Sign Language

Although cliticisation and, to a lesser extent, affixation do occur in sign languages, instances of either morphological process are poorly understood and documented at present. The discussion in this section should therefore be considered preliminary and would need to be followed up on with more individual examples from other sign languages. At this stage, I will limit the discussion to describing examples of what would seem to be a prototypical negative clitic and a prototypical negative affix in a sign language. Other negative morphemes in other sign languages might fall somewhere in between along a continuum of sequential morphological negation, but are not discussed in detail here.

In Türk İşaret Dili (Turkey), the basic clause negator NOT can be cliticised to the preceding sign and then appears in a reduced form. The location in space where the sign is made assimilates to the preceding sign, that is, NOT is signed wherever the preceding sign ends. A two-handed host sign requires the negative 


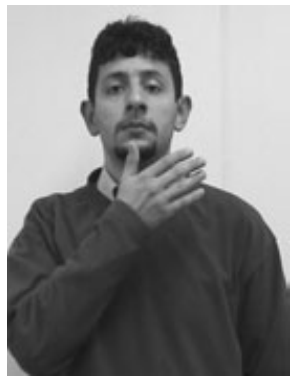

KNOW

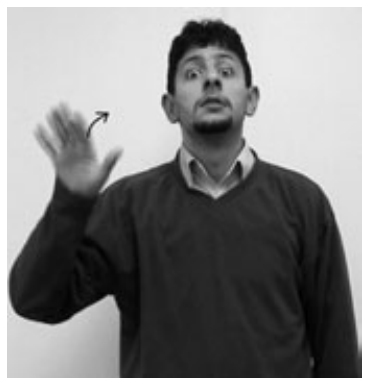

NOT

(a)

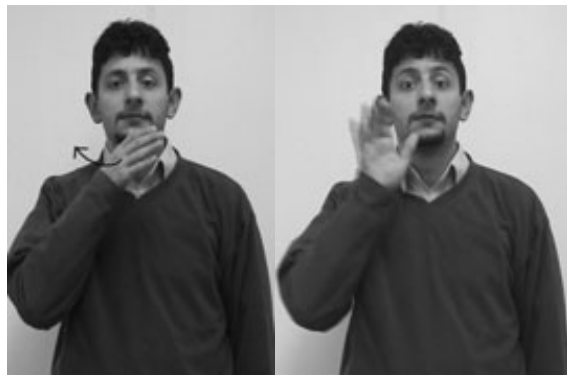

KNOW^NOT

(b)

Figure 19. Negation without and with cliticisation (Türk Işaret Dili, Turkey)

clitic to be two-handed as well, while a one-handed variant of NOT is used with a one-handed host sign. Figure 19 shows the sequence KNOW NOT with NOT in its full form and in its cliticised form. In its full form (Figure 19a), NOT can be one- or two-handed and is articulated in the open space in front of the signer's torso, with a bending of the wrist that changes the orientation of the finger tips from facing downwards to facing upwards. As a clitic (Figure 19b), ${ }^{\wedge}$ NOT consists of just a tiny brief twist of the wrist at the chin location, the same location where the host sign KNOW is articulated. Details of negative cliticisation in Türk İşaret Dili have been described in Zeshan (2003).

The fact that a sign appears in a reduced form would apply to both a clitic and an affix. However, further characteristics distinguish both cases. The negative clitic in Türk İşaret Dili has a co-existing free form with which it alternates. The free form tends to be used for emphasis and with predicates of lesser frequency, while the clitic most commonly occurs with high-frequency predicates such as 'not know', not understand', 'not same', and so on. Despite 


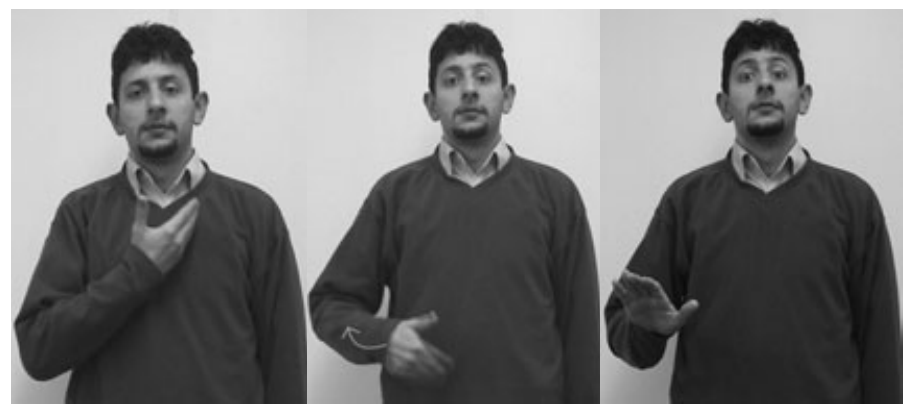

LIKE^NOT

Figure 20. Negative cliticisation in Türk Işsaret Dili (Turkey)

differences in frequency, the possibility of using the clitic form of the negative is very productive, and no general restrictions on the occurrence of the clitic have been identified yet. ${ }^{8}$ As far as the form of the signs is concerned, if the predicate sign has a movement of its own, the host-clitic combination will have two movement components, both reduced in time. Figure 20 shows another example, the sign LIKE with a clitic ${ }^{\wedge} \mathrm{NOT}$, where the movement across the torso belongs to LIKE and the subsequent twist of the wrist belongs to ${ }^{\wedge}$ NOT. Finally, there are no formational changes to either the negative clitic or the host sign other than those that result from temporal compression and the transition between host and clitic. The basic formational parameters of each sign remain intact, and the meaning is always fully predictable.

An example for a negative affix comes from Finnish Sign Language. It differs in a number of properties from the negative clitic in Türk İsaret Dili, all of which indicate a higher degree of fusion between the two morphemes involved. The negative morpheme itself is underspecified. It only consists of a change in palm orientation with, usually, an open handshape. Depending on the preceding stem, the hand ends up either in a horizontal position with the palm facing upwards or in a vertical position with the palm facing inwards. There is no straightforward candidate for a co-existing free negative and consequently no semantically equivalent free alternation between the negative affix and an independent negative. Use of the affix is not productive, but is restricted to a handful of predicates, all of which are high-frequency items. Figures 21 and 22 show two examples of positive-negative pairs. Unlike in the host-clitic combination in Türk İşaret Dili, there are substantial changes to both the stem and

8. This is the only clear case of widespread morphological negation among the sign languages in the data, so unlike all the other negatives discussed in this section, the term "irregular negative" does not really apply to the negative clitic in Türk İşaret Dili. 


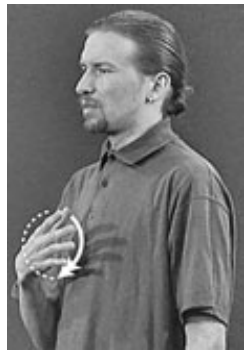

NEED

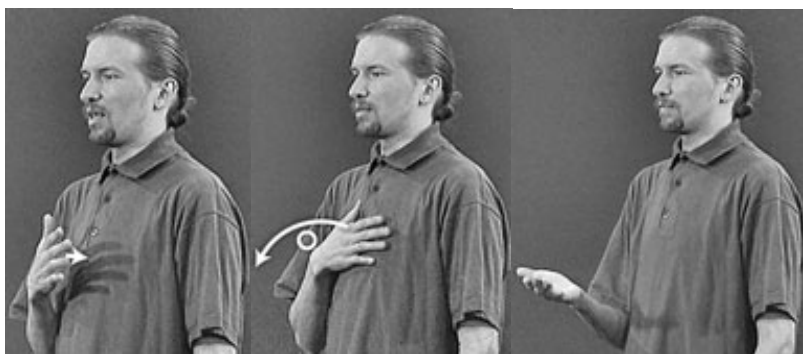

NEED-neg

Figure 21. Negative affix in Finnish Sign Language (1)

the affix. In Figure 21, the sign NEED has a repeated circular movement that is almost entirely lost in the negative, so that the negative only has an outward movement with a brief preceding contact on the chest. Figure 22 shows that the negative form requires a change in hand orientation on the stem SEE, with the palm facing inward in the positive but outward in the negative form. Moreover, the negative affix can optionally assimilate its handshape to the stem, so that the sign ends with either an open hand (the negative's own handshape) or with two fingers extended (the stem sign's handshape). The same alternation occurs with the negative of the sign for 'understand, be able to, know how to'. Finally, the negative results in a semantic change in two cases, with the signs HEAR and SEE. While the positive signs are unspecified for tense or aspect, their negative counterparts carry a perfective/resultative meaning, translating as 'have not heard; do not know' and 'have not seen; did not see'. The differences between the clitic in Türk İşaret Dili and the affix in Finnish Sign Language are summarised in Table 6 .

Bound negative morphemes of the sequential type in other sign languages may fall somewhere in between the prototypical clitic and the prototypical affix described in these two examples, with some characteristics of each type. For example, a negative morpheme which is glossed ZERO in American Sign Language and is described as a suffix in Aronoff, Meir, \& Sandler (2000) does alternate with a co-existing free form, but also exhibits strong constraints with respect to the stem it can combine with, while its productivity is variable. The negative derivational affix +LESS in Israeli Sign Language (Meir 2002) displays some degree of formational assimilation and several instances of idiosyncratic meaning changes (e.g., SHY+LESS 'shameless', SURPRISE+LESS 'doesn't interest me at all'). The sign has probably evolved from one of the negative existentials, and this grammaticalisation process is still very much in progress. 


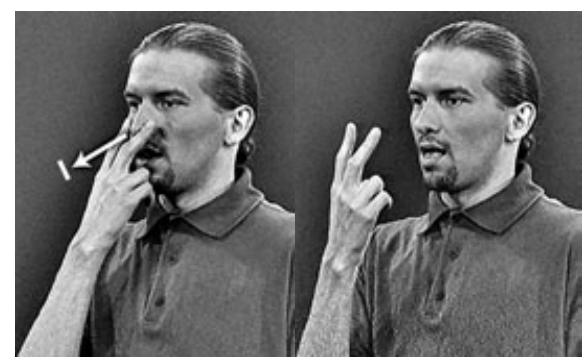

SEE

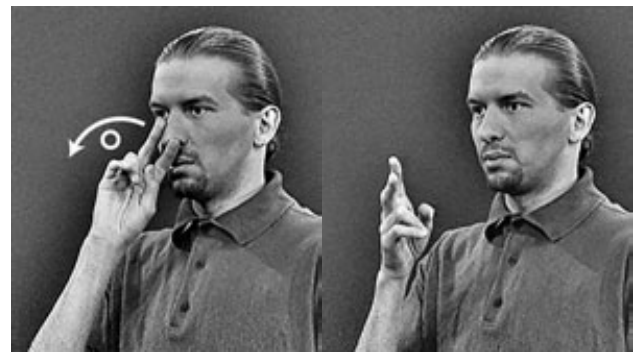

SEE-neg

Figure 22. Negative affix in Finnish Sign Language (2)

Table 6. Negative clitic and negative affix

\begin{tabular}{ll}
\hline $\begin{array}{l}\text { NEGATIVE CLITIC: } \\
\text { Türk İşaret Dili ^NOT }\end{array}$ & $\begin{array}{l}\text { NEGATIVE AFFIX: } \\
\text { Finnish Sign Language -neg }\end{array}$ \\
\hline $\begin{array}{l}\text { co-existing free form } \\
\text { variation between free form and clitic } \\
\text { form }\end{array}$ & $\begin{array}{l}\text { no co-existing free form } \\
\text { no variation between free and bound } \\
\text { form }\end{array}$ \\
$\begin{array}{l}\text { comparatively more productive } \\
\text { form more fully specified } \\
\text { often two separate reduced } \\
\text { movements }\end{array}$ & $\begin{array}{l}\text { comparatively less productive } \\
\text { form less fully specified }\end{array}$ \\
$\begin{array}{l}\text { no handshape assimilation } \\
\text { full compositionality of meaning } \\
\text { no formational changes other than }\end{array}$ & $\begin{array}{l}\text { handshape assimilation possible } \\
\text { reduction }\end{array}$ \\
\hline
\end{tabular}

The problem of classifying a particular negative form with respect to the typology proposed here also holds for other levels of distinctions. Sometimes one 
and the same form can have a different status in two different sign languages. For example, the sign for 'not know' looks the same in Auslan (Australia) and in American Sign Language, with the finger tips of an open hand touching the side of the forehead and moving away while changing hand orientation. However, in American Sign Language, this sign is one of a set of predicates that are morphologically negated by adding an "outward twist of the wrist" morpheme, so that KNOW and KNOW+neg are formationally related and the negative is derived in a regular way. In Auslan (Australia), the positive sign KNOW has a different form that is not related to the negative, and therefore the negative must be considered a monomorphemic suppletive form NOT-KNOW. ${ }^{9}$ This kind of situation can arise when a sign language borrows individual irregular negatives, which seems to be not uncommon, without borrowing the negative derivational process as such. As shown in the lower half of Table 5, each sign language exploits of different range of irregular negatives.

Perhaps the single most striking observation when looking at all kinds of morphological negatives in sign languages together is the regular recurrence of particular items to which morphological negation or negative suppletion applies. The specific semantic and grammatical domains where irregular negatives occur with great regularity across sign languages have been listed in Zeshan (forthcoming) as the following (with examples):

- cognition: not know, not understand

- emotional attitude: not want, not like, not care

- modals: cannot, need not, must not

- possession/existential: not have, not exist, not get

- tense/aspect: will not, did not, not finished

- evaluative judgement: not right, not possible, not enough

Sign languages with very few irregular negatives consistently draw on a very restricted sub-set of this list, which includes the signs for 'want', 'like', 'know', 'can', 'must', 'finish' (completive), and 'exist/have' (existential). These are at the same time the most common irregular negatives across all sign languages.

It may be noted that all items listed here occur with high frequency in natural conversation, which goes a long way towards explaining the pattern. A similar range of irregular negative forms can be found across spoken languages as well, presumably for the same reasons. Obviously, initial phonological assimilation that would later lead to cliticisation and, eventually, to affixation is

9. To add another twist to this situation, Woodward \& deSantis (1977) argue that the outward twist of the wrist was originally a process of phonological assimilation of a negative particle in French Sign Language, corresponding to what I have described as cliticisation here. However, this negative particle was lost in American Sign Language, which is historically related to French Sign Language, so that present-day American Sign Language is left with a negative morpheme that is not related to any free negative. 
greatly facilitated by a high frequency of the items involved. Another aspect of this argument is that the categories where irregular negatives are common are all cognitively very salient. That is, events and states such as 'not liking', 'not knowing', 'not having', and so on, are individually identifiable human experiences, while combinations such as 'not running', 'not red', or 'not a table' have no such privileged status. Therefore, the negatives in the above list are prone either to be lexicalised separately due to their cognitive salience, leading to suppletive negatives, or to be involved in grammaticalisation leading to morphological negation, due to their high frequency.

\section{Conclusion}

It has been the aim of this article to give a broad survey of negation strategies used in sign languages around the world. As a general caveat to the issues discussed and claims made here, it should be noted that the crosslinguistic study of sign languages is still very much a matter of exploration and adventure rather than a field where we can build on established results. Many of the sign languages in the data are severely underdescribed, and there is always room for misinterpretation of individual facts based on insufficient data. ${ }^{10}$ However, I believe that the general picture that has been painted here reflects accurately the range and richness of possible structures that we find across sign languages. It thus seems appropriate to take a final look at how sign languages as a whole compare with spoken languages in the domain of negation. One part of sign language typology is concerned with how different sign languages can be from one another, and this has been the main topic pursued in this article. Another aim is to subsequently compare the range of sign language structures with the range of spoken language structures and arrive at inductive generalisations about what it may mean to say that sign languages constitute a distinct linguistic type. These generalisations are summed up in Table 7.

Sign languages differ strikingly from spoken languages in the kinds of negation strategies that they prefer. In spoken languages, both negative particles and morphological negation in the form of affixing are common negation strategies. The use of a specific negative intonation, on the other hand, is extremely uncommon. Even a change in individual prosodic features such as tone is rare and almost always used in addition to another negative morpheme. By contrast, intonation in the form of head movements is extremely common, in fact universal, across sign languages. Negative particles are also very common, so

10. Details of the methodology of this project, the types of data included, and possible associated limitations are described in Zeshan (2004), along with the measures taken to minimise the adverse effects of these limitations. 
Table 7. Negation in signed and spoken languages

\begin{tabular}{|c|c|c|}
\hline PARAMETER & Spoken languages & Sign languages \\
\hline \multirow[t]{3}{*}{$\begin{array}{l}\text { Frequency of } \\
\text { negation strategies }\end{array}$} & $\begin{array}{l}\text { Morphological negation } \\
\text { (affixing) is general across a } \\
\text { word class and common } \\
\text { across languages. }\end{array}$ & $\begin{array}{l}\text { Morphological negation is } \\
\text { limited. }\end{array}$ \\
\hline & $\begin{array}{l}\text { Negative particles are } \\
\text { common. }\end{array}$ & $\begin{array}{l}\text { Negative particles are very } \\
\text { common. }\end{array}$ \\
\hline & $\begin{array}{l}\text { Intonation is extremely } \\
\text { uncommon. }\end{array}$ & $\begin{array}{l}\text { Intonation is extremely } \\
\text { common. }\end{array}$ \\
\hline $\begin{array}{l}\text { Morphological } \\
\text { negation }\end{array}$ & $\begin{array}{l}\text { Almost always affixation } \\
\text { (both prefixes and suffixes), } \\
\text { other morphological } \\
\text { processes are very rare. }\end{array}$ & $\begin{array}{l}\text { Only suffixation, no prefixes, } \\
\text { plus simultaneous internal } \\
\text { modification of signs. }\end{array}$ \\
\hline $\begin{array}{l}\text { Syntactic position } \\
\text { of negative } \\
\text { particles }\end{array}$ & Predominantly pre-verbal. & Predominantly clause-final. \\
\hline $\begin{array}{l}\text { Double marking of } \\
\text { negation }\end{array}$ & $\begin{array}{l}\text { Relatively uncommon, } \\
\text { especially as a combination } \\
\text { with negative intonation, but } \\
\text { some instances of double } \\
\text { particle constructions. }\end{array}$ & $\begin{array}{l}\text { Extremely common, } \\
\text { especially with manual and } \\
\text { nonmanual negation, but no } \\
\text { double particle construction. }\end{array}$ \\
\hline $\begin{array}{l}\text { Form of negative } \\
\text { morpheme }\end{array}$ & $\begin{array}{l}\text { Arbitrary and not recurrent in } \\
\text { unrelated languages. }\end{array}$ & $\begin{array}{l}\text { Often iconic and recurrent in } \\
\text { unrelated languages. }\end{array}$ \\
\hline
\end{tabular}

that all sign languages have at least one negative particle, and most have several. Morphological negation, on the other hand, is severely limited in most sign languages, with very few cases of comparatively more productive negative morphology.

Where sign languages do have morphological negation, it is often of a different type than morphological negation in spoken language. The latter use either prefixes or suffixes, while other morphological processes, such as infixes, circumfixes, reduplication, ablaut, prosodic change, or any kind of internal stem modification, are very rare or nonexistent. Sign languages exploit quite different means for morphological negation. First of all, they are exclusively suffixing, with no attested case of a negative prefix in our data. Moreover, internal morphological modification of signs is quite common and exists in a number of different variants, such as modification of movement or handshape change. 
A "zero negative", indicated by the absence of a marker for the positive as documented for South Dravidian languages (Master 1946, Pederson 1991), has not been found in any sign language and is unlikely to occur, given the universal availability of nonmanual negation.

As far as negative particles are concerned, spoken languages predominantly have pre-verbal particles, while sign languages have a preference for postpredicate or clause-final position, although other word orders are attested in both signed and spoken languages. The preference for pre-verbal negative particles in spoken languages also and particularly holds for pidgins and creoles (Sebba 1997: 42). Given that sign languages have often been associated with creoles (e.g., Aronoff, Meir, \& Sandler 2000, Newport 1999, Sebba 1997: $269 \mathrm{ff}$.), the difference in preferred word order is even more striking. The interaction between the syntactic position of negative particles and other word order parameters has however not been worked out for sign languages, so more study is needed in this area.

Double or even multiple expression of negation is extremely common in sign languages, and the clause always remains negative as a whole. The most common construction type here is double negative marking in the form of a negative particle plus a nonmanual negative marker. All sign languages seem to allow this construction, and in many cases it is the most common way of expressing negation. Sometimes the negative particle itself is repeated, as in (40) and (41) in Section 3.2, while the combination of two different manual negatives, such as a clause negator and a negative quantifier, is very uncommon. Spoken languages, by contrast, have relatively few instances of double or multiple negation (Dryer 1988). Cases of a negative morpheme combined with a distinctive negative intonation contour, as in the New Ireland language Kuot (Lindström 2002), are extremely rare, although changes in tone on individual segments do occur in a number of languages (Pfau forthcoming). Where double marking of negation does exist in spoken languages, it often takes the form of a combination of two different negative particles, or one particle and one affix. The phenomenon of reinforcing a negative with another has become known as "Jespersen's Cycle", and the "double particle construction" (Dahl 1979: 88-89), as exemplified by French ne .. pas, can be understood by the need to match a very important grammatical category with an adequate amount of linguistic substance (cf. Horn 1989: $452 \mathrm{ff}$.). Curiously, there is not a single case of a double particle construction in our sign language data, although negative particles are extremely common and many sign languages have several such particles. It may be that the use of nonmanual negation as a reinforcement of manual negation (or the other way around) eliminates the cognitive need for double particle constructions.

The interaction between manual and nonmanual negation may also partly explain the different word order preferences for negative particles in signed 
versus spoken languages. Horn (1989: 461-462) points out the virtual absence of clause-initial or clause-final negatives in spoken languages, which contrasts sharply with the extent of clause-final position in sign languages. The close association of verb and negative particle in spoken languages can be replaced in sign languages by nonmanual negation on the verb or predicate, thus eliminating the need for the negative particle to be directly next to the predicate. Nonmanual negation also allows for an expression of negation "early in the clause", if we want to adopt this as a valid principle for negative placement (cf. discussion of the "Neg First" principle in Horn 1989: 445 ff.). On the other hand, clause-final negatives in signed utterances do often end up next to a preceding verb or predicate, due to a number of factors such as topic-comment structures and ellipsis, that cannot be addressed in detail here. Finally, we may have a situation such as in Indo-Pakistani Sign Language, with a generalised clause-final position for all particles indicating clause types, which include existentials, interrogatives, and imperatives as well as negatives.

A final point of comparison concerns the actual form of negatives in signed and spoken languages. It is perhaps trivial to observe that negative morphemes in spoken languages are arbitrary in form and are different from one another in unrelated languages. That is, there is no extra-linguistic reason why negative morphemes are the way they are, and particular negative forms do not systematically recur in unrelated spoken languages. The situation in sign languages is quite different, as has been described in Section 3.1 (see Table 4). Due to widespread iconicity, particular forms do recur in many sign languages that are not genetically or geographically related. Although a common genetic origin and borrowing can also contribute to the sharing of particular negative forms (examples have been given in Section 3.3), there are many cases where the recurrence of the same or similar forms cannot be attributed to either of these factors.

Taking all available evidence into account, it does turn out that sign languages are indeed different from spoken languages in several respects. It also turns out that there is a lot of variation across sign languages and thus a rich array of negative structures. Since there is always more to human language than meets the eye, we can look forward to further studies of sign languages around the world that will undoubtedly uncover many more fascinating facets of this parallel linguistic universe.

Received: 28 June 2002

La Trobe University

Revised: 15 April 2003

Correspondence address: Max Planck Institute for Psycholinguistics, Postbus 310, NL-6500 Nijmegen, The Netherlands; email: ulrike.zeshan@mpi.nl, ulrike.zeshan@yahoo.com 
Acknowledgements: I am grateful to the Research Centre for Linguistic Typology at La Trobe University and its directors, R. M. W. Dixon and A. Aikhenvald, for support of the research project on the typology of negative and interrogative constructions in signed and spoken languages. Siew Peng and Darren Condon have assisted with the development of the MS Access database, and Adam Schembri has acted as test person for the questionnaires. The German Science Foundation is supporting the research project under its post-doctoral "Emmy-Noether" research scheme.

I am indebted to my many sign language informants in Pakistan, India, Turkey, and Lebanon for sharing their language with me. Special thanks are due to all co-researchers who have contributed to the project: Trevor Johnston (Auslan, Australia), Elisabeth Engberg-Pedersen (Dansk Tegnsprog, Denmark), Leena Savolainen, Pia Taalas, Kimmo Leinonen, Kaisa Alanne, Karin Hoyer, Anja Malm (Finnish Sign Language), Ritva Takkinen, with a group of students (Finnish Sign Language), Klimis Antzakas (Greek Sign Language), Gladys Tang, Kenny Chen (Hong Kong Sign Language), Svandís Svavarsdóttir (Íslenskt táknmál, Iceland), Helena Saunders (Irish Sign Language), Irit Meir, Meir Etedgi (Israeli Sign Language), Washington Akaranga (Kenyan Sign Language), Ronice Mueller de Quadros (Língua de Sinais Brasileira, Brazil), Rachel McKee (New Zealand Sign Language), Michael Morgan (Nihon Shuwa, Japan), Sean Witty, Cho Wiyoung Witty (South Korean Sign Language), Inmaculada Baez, Carmen Cabeza, Ana Fernández-Soneira, Mar Lourido-Francisco, Juan Valiño-Freire - Grupo de Investigación sobre Lengua de Señas, Universidad de Vigo (Lengua de Señas Española, Spain), Wayne Smith (Taiwanese Sign Language), Nicholaus Mpingwa (Lugha ya Alama Tanzania), Sam Lutalo (Ugandan Sign Language), Myriam Vermeerbergen, Diane Boonen (Vlaamse Gebarentaal, Belgium).

I also thank the deaf individuals I filmed during the World Federation of the Deaf congress in Brisbane in 1999 and whose data I have used for the project: Kanitha Ratanasint (Thailand), Margaret Mukami, Nickson Akiri (Kenya), Lupi Maswaya (Tanzania), Tanya Davidenko (Russia).

Notation and transcription conventions: All transcribed examples have been translated into English if the original was in another language, and the glossing of frequently occurring signs has been standardised. Words in capital letters represent the signs, with nonmanual signals noted on top of these at the end of a line indicating the scope of the signal. Single sign glosses that consist of more than one English word are transcribed with hyphens (e.g., NOT-YET, WE-TWO), complex signs are transcribed with a 'plus' symbol (e.g., HOUSE+SLEEP, CAN+NOT). In the graphics, a star indicates contact, and arrows indicate movement of the hand. An arrow with a circle around its arm indicates wrist twisting.

The following abbreviations and symbols have been used in the transcriptions, (i) on the line glossing the signs and (ii) on the line noting the nonmanual signals:

(i) $\mathrm{r}$

$1 \quad$ left

fr forward right

fl forward left

upr up right

INDEX1 1st person pronoun

INDEX2 2nd person pronoun

INDEX3 3rd person pronoun

2:VISIT:1 verb agreement

"speak" mimed action

T-E-A manual alphabet (fingerspelling)

NOT clitic

NEG negative

(ii) $\mathrm{y} / \mathrm{n} \quad$ polar (yes/no-) question

face-neg negative facial expression

$\mathrm{t}$ topic 


\section{References}

Akach, Philemon (ed.) (1991). Kenyan Sign Language Dictionary. Nairobi: Kenya National Association of the Deaf.

Antzakas, Klimis (2002). The use of negative head movements in Greek Sign Language. Manuscript, City University, London.

Armstrong, David F. (1983). Iconicity, arbitrariness, and duality of patterning in signed and spoken language: Perspectives on language evolution. Sign Language Studies 3: 51-69.

Armstrong, David F., William C. Stokoe, \& Sherman E. Wilcox (1995). Gesture and the Nature of Language. Cambridge: Cambridge University Press.

Aronoff, Mark, Irit Meir, \& Wendy Sandler (2000). Universal and particular aspects of sign language morphology. UMD (University of Maryland) Working Papers in Linguistics 10: 1-33.

Baker, Charlotte \& Carol A. Padden (1978). Focusing on the nonmanual components of American Sign Language. In Patricia Siple (ed.), Understanding Language through Sign Language Research, 27-58. New York: Academic Press.

Baker-Shenk, Charlotte \& Dennis Cokely (1996). American Sign Language: A Teacher's Resource Text on Grammar and Culture. Washington: Gallaudet University Press.

Bellugi, Ursula \& Susan Fischer (1972). A comparison of sign language and spoken language: Rate and grammatical mechanisms. Cognition 1: 173-200.

Bellugi, Ursula \& Edward S. Klima (1990). Properties of visual spatial languages. In Siegmund Prillwitz \& Tomas Vollhaber (eds.), Sign Language Research and Application: Proceedings of the International Congress on Sign Languages Research and Application, March 23-25, 1990 in Hamburg, 115-143. Hamburg: Signum.

Bergman, Brita (1995). Manual and nonmanual expression of negation in Swedish Sign Language. In Heleen Bos \& Trude Schermer (eds.), Sign Language Research 1994: Proceedings of the 4th European Congress on Sign Language Research, Munich, September 1-3, 1994, 85-103. Hamburg: Signum.

Berthiaume, Rachel \& Julie Rinfret (2000). La négation en langue des signes québécoise (LSQ). Manuscript, Université du Québec à Montréal.

Branson, Jan, Don Miller, I Gede Marsaja, \& I Wayan Negara (1996) Everyone here speaks Sign Language too: A deaf village in Bali, Indonesia. In Ceil Lucas (ed.), Multicultural Aspects of Sociolinguistics in Deaf Communities, 39-57. Washington: Gallaudet University Press.

CHAVITA (Chama cha Viziwi Tanzania/Tanzania Association of the Deaf) (1993). Kamusi ya Lugha ya Alama Tanzania. The Tanzania Sign Language Dictionary. Dar-es-Salaam: Tanzania Association of the Deaf (Chavita).

Coerts, Jane (1992). Nonmanual grammatical markers: An analysis of interrogatives, negations and topicalisations in Sign Language of the Netherlands. Doctoral dissertation, Universiteit van Amsterdam.

Dahl, Östen (1979). Typology of sentence negation. Linguistics 17: 79-106.

DeMatteo, Asa (1977). Visual imagery and visual analogues in American Sign Language. In Friedman 1977, 109-136.

Dotter, Franz (2001). Gebärdensprachforschung. In Martin Haspelmath, Ekkehard König, Wulf Oesterreicher, \& Wolfgang Raible (eds.), Language Typology and Language Universals: An International Handbook, 141-154. Berlin: de Gruyter.

Dotter, Franz \& Daniel Holzinger (1995). Typologie und Gebärdensprache: Sequentialität und Simultanität. Sprachtypologie und Universalienforschung 48: 311-349.

Dryer, Matthew (1988). Universals of negative position. In Michael Hammond, Edith Moravcsik, \& Jessica Wirth (eds.), Studies in Syntactic Typology, 93-124. Amsterdam: Benjamins.

Emmorey, Karen \& Judy S. Reilly (eds.) (1995). Language, Gesture, and Space. Hillsdale, N.J.: Lawrence Erlbaum.

Engberg-Pedersen, Elisabeth (1990). Pragmatics of nonmanual behaviour in Danish Sign Language. In William H. Edmondson \& Fred Karlsson (eds.), SLR '87: Papers from the Fourth 
International Symposium on Sign Language Research. Lappeenranta, Finland, July 15-19, 1987, 121-128. Hamburg: Signum.

Friedman, Lynn A. (ed.) (1977). On the Other Hand: New Perspectives on American Sign Language. New York: Academic Press.

Grimes, Barbara F. (ed.) (1996). Ethnologue: Languages of the World. 13th edition. Dallas: Summer Institute of Linguistics.

Horn, Laurence R. (1989). A Natural History of Negation. Chicago: University of Chicago Press.

Hovdhaugen, Even \& Ulrike Mosel (eds.) (1999). Negation in Oceanic Languages: Typological Studies. München: Lincom Europa.

Kahrel, Peter \& René van den Berg (eds.) (1994). Typological Studies in Negation. Amsterdam: Benjamins.

Karlsson, Fred (1984). Structure and iconicity in Sign Language. In Filip Loncke, Penny BoyesBraem, \& Yvan Lebrun (eds.), Recent Research on European Sign Languages, 149-155. Lisse, Netherlands: Swets \& Zeitlinger

Lindström, Eva (2002). Topics in the grammar of Kuot, a non-Austronesian language of New Ireland, Papua New Guinea. Doctoral dissertation, Stockholm University.

Mandel, Mark (1977). Iconic devices in American Sign Language. In Friedman (ed.), 57-107.

McKee, Rachel (2002). Aspects of interrogatives and negation in New Zealand Sign Language. Manuscript, Victoria University of Wellington.

Meir, Irit (2002). Question and negation in Israeli Sign Language. Manuscript, University of Haifa. Moody, Bill, Dominique Hof, \& Serge Dumartin (1983). La langue des signes. Tome 1: Histoire et Grammaire. Vincennes, France: International Visual Theatre - Centre Socio-Culturel des Sourds.

Morris, Desmond (1979). Gestures: Their Origins and Distribution. London: Cape.

Newport, Elissa L. (1999). Reduced input in the acquisition of signed languages: Contribution to the study of creolization. In Michel DeGraff (ed.), Language Creation and Language Change, 161-178. Cambridge, Mass.: MIT Press.

Payne, John R. (1985). Negation. In Timothy Shopen (ed.), Language Typology and Syntactic Description, Volume 1: Clause Structure, 197-242. Cambridge: Cambridge University Press.

Pfau, Roland (forthcoming). De grammatica van het hoffdschudden: Zinsontkenning in de Duitse Gebarentaal. To appear in: Gramma TTT.

Pizzuto, Elena, Enza Giuranna, \& Giuseppe Gambino (1990). Manual and nonmanual morphology in Italian Sign Language: Grammatical constraints and discourse processes. In Ceil Lucas (ed.), Sign Language Research: Theoretical Issues, 83-102. Washington: Gallaudet University Press.

Radutzky, Elena, Benedetto Santarelli, \& Susanna Suatoni (1992). Dizionario bilingue elementare della lingua italiana dei segni. Roma: Kappa.

Sandler, Wendy (1999). The medium and the message: Prosodic interpretation of linguistic content in Israeli Sign Language. Sign Language and Linguistics 2: 187-215.

Sebba, Mark (1997). Contact Languages: Pidgins and Creoles. London: Macmillan.

Stokoe, William (1978). Sign language versus spoken language. Sign Language Studies 18: 69-90.

Sutton-Spence, Rachel \& Bencie Woll (1999). The Linguistics of British Sign Language: An Introduction. Cambridge: Cambridge University Press.

Suwanarat, Manfa \& Charles Reilly (eds.) (1986). The Thai Sign Language Dictionary. Book One. Bangkok: National Association of the Deaf.

Vogt-Svendsen, Marit (1990). Interrogative strukturer i Norsk tegnspråk. [Interrogative structures in Norwegian Sign Language.] Doctoral dissertation, Universitetet i Trondheim.

- (2000). Negation in Norwegian Sign Language and in contrast to some features in German Sign Language. Poster presented at the Theoretical Issues in Sign Language Research (TISLR7) conference in Amsterdam, July 2000.

Webb, Rebecca \& Ted Supalla (1994). Negation in international sign. In Inger Ahlgren, Brita Bergman, \& Mary Brennan (eds.): Perspectives on Sign Language Structure: Papers from the 
Fifth International Symposium on Sign Language Research, Vol. 1, 173-185. International Sign Linguistics Association \& Deaf Studies Research Unit, University of Durham.

Whaley, Lindsay J. (1997). Introduction to Typology: The Unity and Diversity of Language. Thousand Oaks, Cal.: Sage.

Woodward, James \& Susan deSantis (1977). Negative incorporation in French and American Sign Language. Language in Society 6: 379-388.

Yang, Jun Hui \& Susan Fischer (2002). Expressing negation in Chinese Sign Language. Sign Language and Linguistics 5: 167-202.

Zanuttini, Raffaella (1997). Negation and Clausal Structure: A Comparative Study of Romance Languages. Oxford: Oxford University Press.

Zeshan, Ulrike (2000a). Sign Language in Indopakistan: A Description of a Signed Language. Amsterdam: Benjamins.

- (2000b). Gebärdensprachen des indischen Subcontinents. München: Lincom Europa.

- (2003). Aspects of Türk İşaret Dili (Turkish Sign Language). Sign Language and Linguistics 6: 43-75.

- (2004). Interrogative constructions in sign languages - Cross-linguistic perspectives. Language 80: $1-33$.

- (forthcoming). Sign languages. In Matthew Dryer, David Gil, \& Martin Haspelmath (eds.), World Atlas of Language Structures. Oxford: Oxford University Press. 